\title{
Bladder, Bowel, and Sexual Dysfunction in Parkinson's Disease
}

\author{
Ryuji Sakakibara, ${ }^{1}$ Masahiko Kishi, ${ }^{1}$ Emina Ogawa, ${ }^{1}$ Fuyuki Tateno, ${ }^{1}$ Tomoyuki Uchiyama, ${ }^{2}$ \\ Tatsuya Yamamoto, ${ }^{2}$ and Tomonori Yamanishi ${ }^{3}$
}

${ }^{1}$ Neurology Division, Department of Internal Medicine, Sakura Medical Center, Toho University, 564-1 Shimoshizu, Sakura 285-8741, Japan

${ }^{2}$ Department of Neurology, Chiba University, Chiba 263-8522, Japan

${ }^{3}$ Department of Urology, Dokkyo Medical University, Tochigi 321-0293, Japan

Correspondence should be addressed to Ryuji Sakakibara, sakakibara@sakura.med.toho-u.ac.jp

Received 17 October 2010; Revised 6 May 2011; Accepted 30 May 2011

Academic Editor: Irena Rektorova

Copyright () 2011 Ryuji Sakakibara et al. This is an open access article distributed under the Creative Commons Attribution License, which permits unrestricted use, distribution, and reproduction in any medium, provided the original work is properly cited.

\begin{abstract}
Bladder dysfunction (urinary urgency/frequency), bowel dysfunction (constipation), and sexual dysfunction (erectile dysfunction) (also called "pelvic organ" dysfunctions) are common nonmotor disorders in Parkinson's disease (PD). In contrast to motor disorders, pelvic organ autonomic dysfunctions are often nonresponsive to levodopa treatment. The brain pathology causing the bladder dysfunction (appearance of overactivity) involves an altered dopamine-basal ganglia circuit, which normally suppresses the micturition reflex. By contrast, peripheral myenteric pathology causing slowed colonic transit (loss of rectal contractions) and central pathology causing weak strain and paradoxical anal sphincter contraction on defecation (PSD, also called as anismus) are responsible for the bowel dysfunction. In addition, hypothalamic dysfunction is mostly responsible for the sexual dysfunction (decrease in libido and erection) in PD, via altered dopamine-oxytocin pathways, which normally promote libido and erection. The pathophysiology of the pelvic organ dysfunction in PD differs from that in multiple system atrophy; therefore, it might aid in differential diagnosis. Anticholinergic agents are used to treat bladder dysfunction in PD, although these drugs should be used with caution particularly in elderly patients who have cognitive decline. Dietary fibers, laxatives, and "prokinetic" drugs such as serotonergic agonists are used to treat bowel dysfunction in PD. Phosphodiesterase inhibitors are used to treat sexual dysfunction in PD. These treatments might be beneficial in maximizing the patients' quality of life.
\end{abstract}

\section{Introduction}

Parkinson's disease (PD) is a common movement disorder associated with the degeneration of dopaminergic neurons in the substantia nigra. In addition to the movement disorder, patients with PD often show nonmotor disorders. The nonmotor problems of PD include neuropsychiatric disorders, sleep disorders, sensory symptoms, and autonomic disorders [1]. Bladder, bowel, and sexual dysfunction (also called "pelvic organ" dysfunctions) is one of the most common autonomic disorders $[2,3]$. Studies have shown that the pelvic organ dysfunctions have great significance in relation to quality-of-life measures, early institutionalization, and health economics $[4,5]$. It is particularly important to note that, unlike motor disorder, pelvic organ dysfunctions are often nonresponsive to levodopa, suggesting that they occur through a complex pathomechanism [6]. This is because pathology of PD is not confined to the degeneration of dopaminergic neurons in the substantia nigra, and involves other locations in the brain and other neurotransmitter systems than the dopaminergic system. For this reason, add-on therapy is required to maximize patients' quality of life. This article reviews pelvic organ dysfunctions in PD, with particular reference to neural control of the bladder [2], bowel [2], and genital organs, symptoms, objective assessment, and treatment.

\section{Bladder Dysfunction in PD}

2.1. Neural Control of Micturition: Normal Micturition and Detrusor Overactivity. The lower urinary tract (LUT) consists of two major components, the bladder and urethra. 
The bladder has abundant muscarinic M2, 3 receptors and adrenergic beta 3 receptors, and is innervated by cholinergic (parasympathetic) and noradrenergic (sympathetic) fibers for contraction and relaxation, respectively [7]. The urethra has abundant adrenergic alpha $1 \mathrm{~A} / \mathrm{D}$ receptors and nicotinic receptors, and is innervated by noradrenergic (sympathetic; contraction) and cholinergic (somatic; contraction) fibers (Figure 1). The LUT performs two opposite functions, storage and emptying of urine, both of which require an intact neuraxis that involves almost all parts of the nervous system [8]. This is in contrast to postural hypotension, which arises due to lesions below the medullary circulation center in humans [9].

Normal urinary storage is dependent on the sacral autonomic reflex $[7,10]$. The storage reflex is thought to be tonically facilitated by the brain, particularly the pontine storage center $[11,12]$. The pontine storage center lies just ventrolateral to the pontine micturition center (PMC). In addition to the pontine storage center, the storage function is facilitated by the hypothalamus, cerebellum, basal ganglia, and frontal cortex. These areas have been shown to be activated during urinary storage by functional neuroimaging in humans [13]. Normal micturition is dependent on the spino-bulbo-spinal autonomic reflex [7], which particularly involves the midbrain periaqueductal gray matter (PAG) [14-17] and the PMC [7, 11]. The PAG is thought to be central in regulating micturition and has a range of inputs from the higher structures. The PMC is located in or adjacent to the locus coeruleus [18-20]. The PMC is thought to project spinal descending fibers containing glutamate as a facilitatory neurotransmitter, which activates the sacral bladder preganglionic nucleus [21]. PMC also projects fibers containing $\gamma$-amino-butyric acid (GABA) and glycine as inhibitory neurotransmitters, which suppresses the sacral urethral motor nucleus (the Onuf's nucleus) [22]. The voiding function seems to be initiated and facilitated by the higher brain structures, for example, the hypothalamus and prefrontal cortex, which seem to overlap in the storagefacilitating area $[13,23]$. Bladder (detrusor) overactivity (DO) is the major cause of urinary urgency/frequency and incontinence [24]. In lesions above the brainstem, the micturition reflex arc is intact, where DO is considered an exaggerated micturition reflex [24-26]. The exaggeration of the micturition reflex might be brought about by more than simply the decreased inhibition of the brain, and might be further facilitated by glutamatergic and D2 dopaminergic mechanisms [27].

2.2. Basal Ganglia Circuit and Dopamine. The net effect of the basal ganglia on micturition is thought to be inhibitory (Figure 2) [7, 28-30]. Functional neuroimaging during bladder filling results in activation in the globus pallidus of normal volunteers [31] and in the putamen in patients with PD [32]. In contrast, dopamine transporter imaging was lower in PD patients with urinary dysfunction than in those without it $[33,34]$. Electrical stimulation of the substantia nigra pars compacta $(\mathrm{SNc})$ inhibited the micturition reflex $[35,36]$, and striatal dopamine levels in situ significantly increased in the urinary storage phase in experimental animals [37]. The micturition reflex is under the influences of dopamine (both inhibitory in D1 and facilitatory in D2) and GABA (inhibitory) [7, 28]. Both the SNc neuronal firing and the released striatal dopamine seem to activate the dopamine D1-GABAergic direct pathway (Figure 2), which not only inhibits the basal ganglia output nuclei, but also may inhibit the micturition reflex via GABAergic collateral to the micturition circuit [37-40]. In patients with PD, disruption of this pathway may lead to DO and resultant urinary urgency/frequency. In addition to the nigrostriatal fibers, the ventral tegmental area (VTA)-mesolimbic dopaminergic fibers are thought to be involved in the control of micturition $[36,41,42]$ (Figure 1).

\subsection{Bladder Dysfunction in PD}

2.3.1. Lower Urinary Tract Symptom. The reported prevalence of LUT symptoms (LUTS) in patients with PD ranges from $38 \%$ to $71 \%$ [43-48]. However, it has been difficult to determine to what extent PD contributes to LUTS. Men older than 60 years of age may have bladder outlet obstruction due to prostate hyperplasia. Women may have stress urinary incontinence. "Idiopathic DO" [10] may occur in men and women older than 65 years due in part to latent brain ischemia [49]. Some of the studies were published before the diagnosis of multiple system atrophy (MSA) [50] was recognized. In recent studies of PD patients who were diagnosed according to modern criteria [5, 51-53], the prevalence of LUTS was found to be $27-63.9 \%$ using validated questionnaires [51-53], or $53 \%$ in men and $63 \%$ in women using a nonvalidated questionnaire that includes a urinary incontinence category [5], with all of these values being significantly higher than the incidence rates in healthy controls. The majority of patients had onset of bladder dysfunction after appearance of motor disorder. Correlations have been shown between bladder dysfunction in patients with PD and neurological disability [51], and bladder dysfunction and stage of disease [5], both suggesting a relationship between dopaminergic degeneration and LUTS. However, Campos-Sousa and colleagues did not find such a correlation [53].

2.3.2. Storage Symptoms. LUTS are divided majorly into two; storage symptoms and voiding symptoms. Storage symptoms are the most common of the LUTS symptom types in PD. Storage symptoms include nocturia (nighttime urinary frequency), which is the most prevalent symptom reported by patients with PD $(>60 \%)$ [5, 51-53]. Patients also complain of urinary urgency $(33-54 \%)$ and daytime frequency $(16-36 \%)$. Urinary incontinence was present in $26 \%$ of male and $28 \%$ of female patients with PD [5].

2.3.3. Voiding Symptoms. Although less common than storage symptoms, voiding symptoms also occur in PD patients. In the study by Sakakibara and colleagues, PD patients had significantly higher rates of retardation in initiating urination (44\% of men only), prolongation/poor stream 


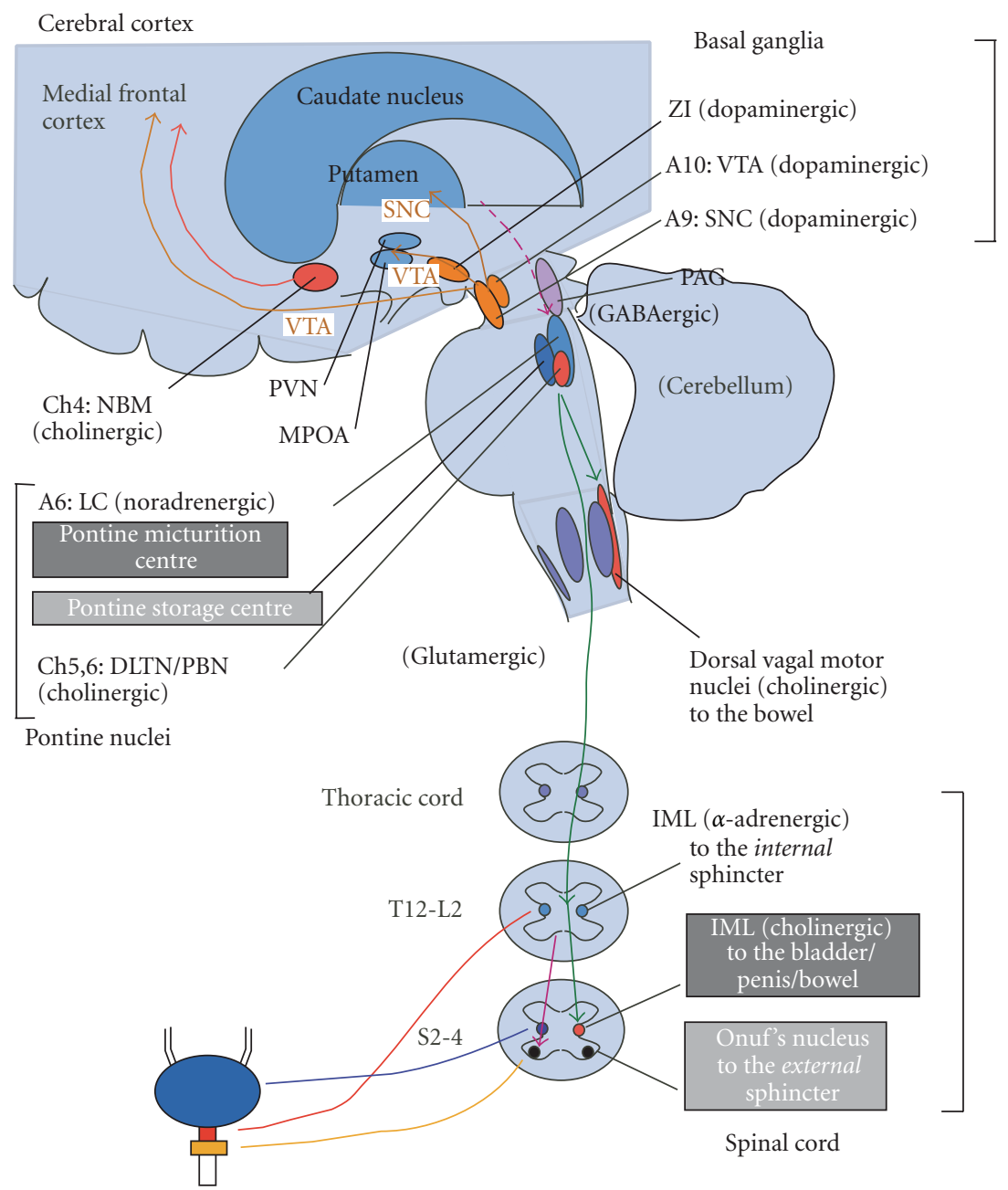

FIgURE 1: Neural circuitry relevant to micturition. PAG, periaqueductal gray; LC, locus ceruleus; NBM, nucleus basalis Meynert; PVN, paraventricular nucleus; MPOA, medial preoptic area; A, adrenergic/noradrenergic; ZI, zona incerta; VTA, ventral tegmental area; SNC, substantia nigra pars compacta; DLTN, dorsolateral tegmental nucleus; PBN, parabrachial nucleus; IML, intermediolateral cell column; GABA, $\gamma$-aminobutyric acid; T, thoracic; L, lumbar; S, sacral. See text.

( $70 \%$ of men only), and straining ( $28 \%$ of women only) compared with the control group [5]. Araki and colleagues noted a correlation between voiding symptoms and stage of disease [54]. However, despite the voiding symptoms, PD patients have low postvoid residuals [5].

\subsubsection{Videourodynamics, Pressure-Flow Analysis, and Sphincter Electromyography}

Bladder (Detrusor) Overactivity. The storage-phase urodynamic abnormalities in PD include reduced bladder capacity together with detrusor overactivity (DO) in 45-93\% [43, $44,54-58]$ of patients, and uninhibited external sphincter relaxation in 33\% [53] of patients (Figure 3). Therefore, DO can be the major contributing factor to overactive bladder in PD. There is also a correlation between DO and stage of disease [55].
Mild, Weak Detrusor, and Sphincter Obstruction. Pressureflow analysis $[10,59,60]$ of the voiding phase in PD has shown weak detrusor activity during voiding $(40 \%$ of men; $66 \%$ of women) [56]. There is a correlation between a weak detrusor and the stage of the disease [55]. A subset of PD patients had DO during storage but weak detrusor activity in voiding. This combination has recently been estimated to occur in 18\% of patients with PD [61]. Some older studies described detrusor-external sphincter dyssynergia or pseudodyssynergia in $\mathrm{PD}$, and these findings were attributed to PD by analogy with bradykinesia of the limbs [62]. However, in our patients with PD, detrusorexternal sphincter dyssynergia was rare [56]. In contrast, a pressure-flow analysis in $\mathrm{PD}$ revealed that half of the patients with PD showed mild urethral obstruction [56]. Patients with PD are reported to have high resting urethral pressure, probably as a result of medication-that is, levodopa and its metabolites, such as norepinephrine. Irrespective of voiding 


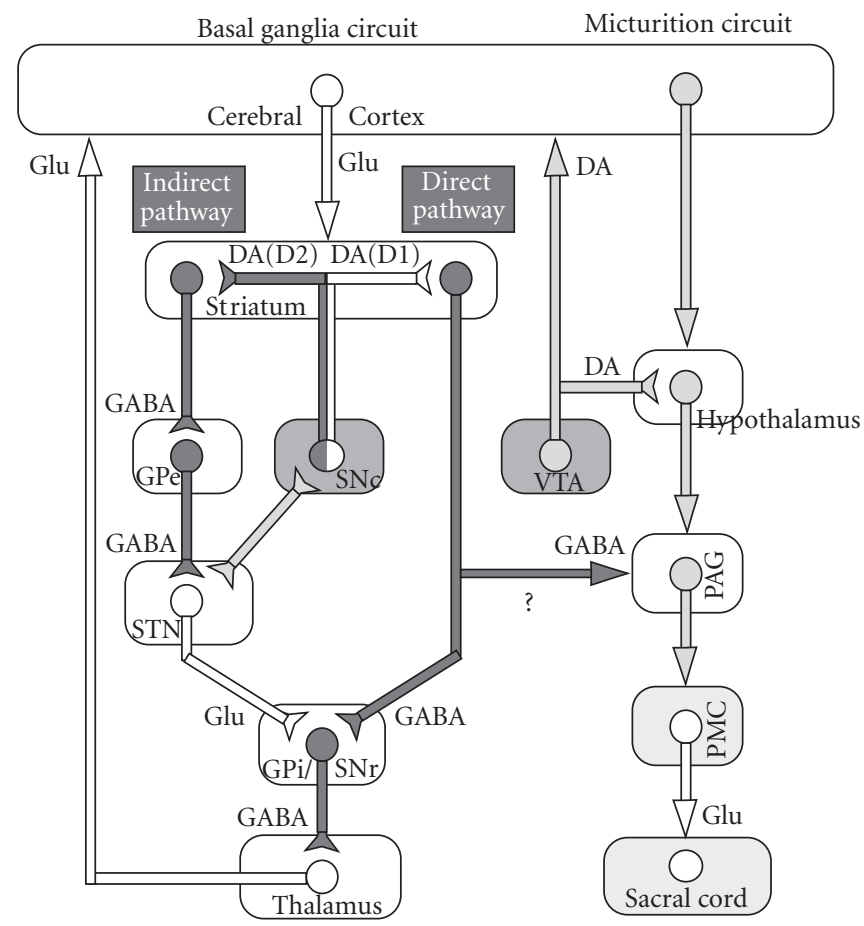

FIgure 2: Possible relationship between basal ganglia circuit (left side) and micturition circuit (right side; modified from Sakakibara et al. [39]). DA, dopamine; GABA, gamma-aminobutyric acid; SNc, substantia nigra pars compacta; GPi, globus pallidus internus; SNr, substantia nigra pars reticulate; STN, subthalamic nucleus; GPe, globus pallidus externus; VTA, ventral tegmental area; PMC, pontine micturition centre; Glu, glutamate; black line, inhibitory neurons; white line, excitatory neurons; hatched line, neurons of undetermined property. The micturition reflex (right-side pathway) is under the influences of dopamine (DA; both inhibitory in D1 and facilitatory in D2) and gammaaminobutyric acid (GABA; inhibitory). The substantia nigra pars compacta (SNc) neuronal firing and the released striatal dopamine seem to activate the dopamine D1-GABAergic direct pathway, which not only inhibits the basal ganglia output nuclei (e.g., the globus pallidus internus (GPi), substantia nigra pars reticulata $(\mathrm{SNr})$ ), but also may inhibit the micturition reflex via GABAergic collateral to the micturition circuit. High-frequency stimulation (leading to inhibition) in the subthalamic nucleus (STN) also results in bladder inhibition. See text.

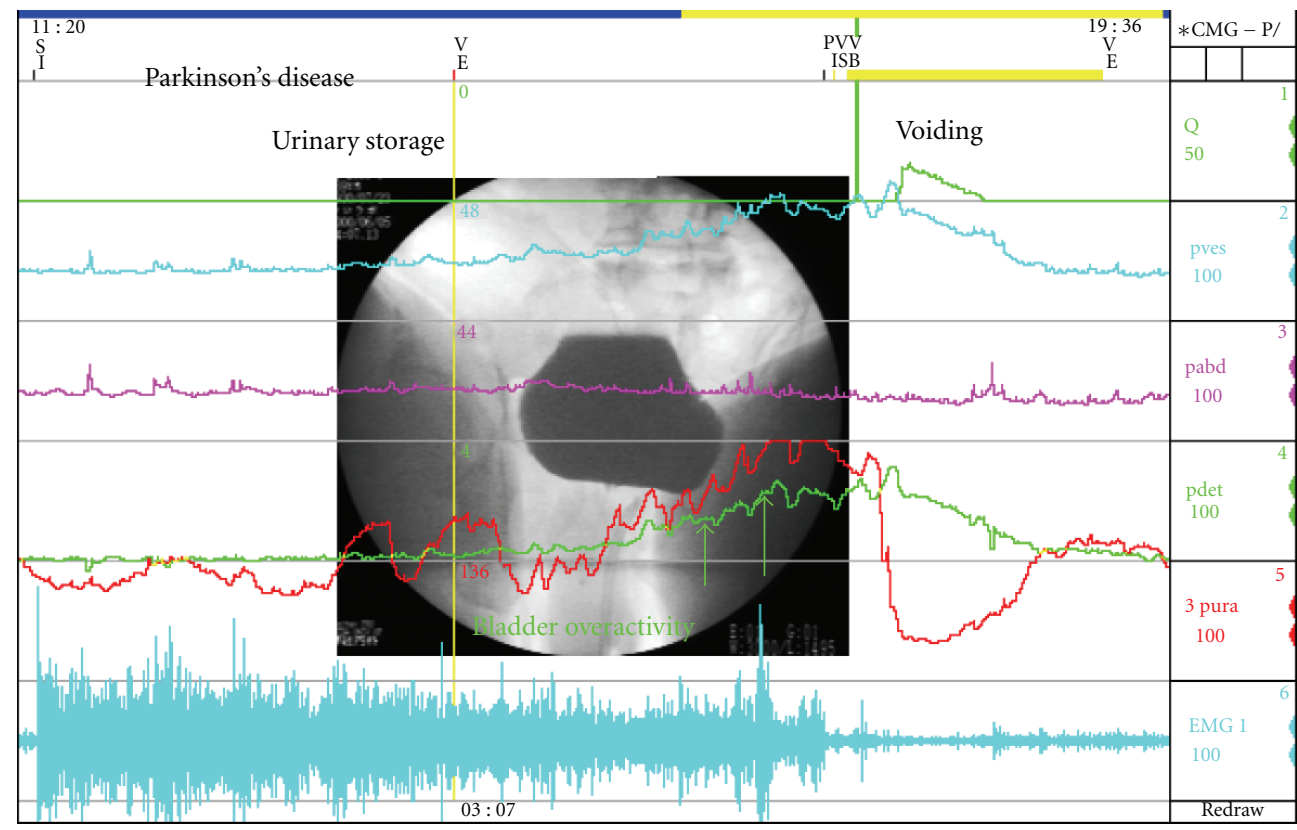

FIGURE 3: Detrusor (bladder) overactivity by urodynamic measurement. 
symptoms in PD, the average volume of postvoid residuals in $\mathrm{PD}$ was as small as $18 \mathrm{~mL}$ [56].

Differential Diagnosis of Parkinsonism by Bladder Dysfunction. In the differential diagnosis of $\mathrm{PD}$ and parkinsoniantype MSA, large postvoid residuals, open bladder neck, and neurogenic change in sphincter motor unit potentials are all common in MSA [56, 63] whereas they are rarely seen in clinically typical PD. However, recent evidence suggests that PD with dementia, or dementia with Lewy bodies [64], may have large postvoid residuals and neurogenic change in the sphincter motor unit potentials [65], thereby mimicking MSA.

\subsection{Treatment of Bladder Dysfunction in PD}

2.4.1. Dopaminergic Drugs. It is possible that levodopa and other antiparkinson medication may affect bladder function in PD. Aranda and Cramer [66] studied the effects of 3-8 mg apomorphine injection on the storage function in 2 de novo PD patients, and found that the bladder capacity increased. They gave oral levodopa to one of the patients, and the bladder capacity increased. We compared the frequency of bladder dysfunction in de novo PD and PD with levodopa. In that study, LUTS was less frequent than in the treated group [59]. In another study, after 3 months of treatment with levodopa, the storage urodynamic parameters were slightly improved in de novo PD [67].

In contrast, in treated patients, studies concerning the effect of dopaminergic drugs on micturition have produced conflicting results. Regarding overactive bladder, some reports have shown a storage-facilitating effect of dopaminergic drugs [5]. In contrast, Kuno and colleagues showed that a change in medication from bromocriptine (D2 selective agonist) to pergolide (D1 < 2 agonist) brought lessening of nocturia [68], and Yamamoto described improvement of DO by pergolide [69]. Benson and colleagues [70] gave $2000 \mathrm{mg}$ of levodopa in 2 longstanding PD patients, and bladder capacity increased in both patients. After discontinuation of levodopa, the bladder capacity further increased in one of the patients, but decreased in the other. Other reports have shown a voiding-facilitating effect of dopaminergic drugs [71]. Fitzmaurice and colleagues [72] have described that, in advanced PD with the on-off phenomenon, DO worsened with levodopa in some patients and lessened in others. Winge and colleagues [73] found that the effect on micturition of treatment with dopaminergic drugs in PD was unpredictable. Recent studies have shown that in early PD [74] and advanced PD with the on-off phenomenon [6], a single dose of levodopa exacerbates DO in the filling phase. We still do not know the exact reasons for the discrepancy.

There are several factors underlying the complex bladder behavior in treated PD patients [75]. Postsynaptic dopamine D1 (excitatory) and D2 (inhibitory) receptors have a millimolar affinity to dopamine whereas dendritic D2 (inhibitory) autoreceptors have a picomolar affinity to dopamine [76]. Therefore, levodopa may first stimulate dendritic D2 autoreceptors, which might suppress the dopaminergic cells and facilitate the micturition reflex. In cases of PD under long-term treatment with levodopa, dopamine receptors are downregulated and potential hypersensitivity might occur [77]. The A11 dopaminergic cell group lies in the dorsal-posterior hypothalamus, which is affected in marmosets with MPTP-induced parkinsonism [78]. This cell group descends as the sole source of spinal dopamine [79], which might also involve in generating bladder overactivity [80]. Peripheral dopamine D1 and D2 receptors also exist in the bladder [81], although their exact role has not been delineated.

2.4.2. Cholinergic Drugs. Anticholinergics [82] are generally used as a first-line treatment for overactive bladder. However, it is important to balance the therapeutic benefits of these drugs with their potential adverse effects. When the dose of drug increases, postvoid residuals may appear [75]. Dry mouth and constipation are common [83]. Cognitive adverse events by anticholinergics are a concern particularly in the elderly. For example, trihexyphenidyl (for PD) and oxybutynin (for overactive bladder) have been shown to have central side effects $[84,85]$. Factors contributing to the central effects of drugs may include blood-brain barrier (BBB) penetration [86]. Among the factors of $\mathrm{BBB}$ penetration, diffusion is facilitated by lipophilicity [87]. Particularly in elderly patients who have hallucinations or cognitive decline (PD with dementia/dementia with Lewy bodies) [64, 65], anticholinergics should be used with extreme caution.

2.4.3. Other Treatments. When a first-line treatment fails or is contraindicated, a second-line treatment might be considered. The main action of central 5-hydroxytryptamine- (5HT, or serotonin-) ergic neurons on the LUT is facilitation of urine storage [88]. In PD, neuronal cell loss in the raphe nucleus has been documented [89]. Therefore, serotonergic drugs, such as duloxetine and milnacipran [90] can be a choice to treat overactive bladder in PD. Nocturnal polyuria should be distinguished from overactive bladder. In patients with PD, the imbalance between diurnal and nocturnal production of urine can be observed in the course of the disease [91]. Treatment with desmopressin proved to be effective in reducing nocturia in PD [92], although this medication needs caution of water intoxication. The subthalamic nucleus (STN) is regarded as the key area in the indirect pathway, which is dominant in the parkinsonian state [93]. Deep brain stimulation (DBS) in the STN inhibits many cells within the STN, probably due to depolarization block and release of GABA from activation of inhibitory afferent terminals [94]. In the STN, neuronal firings related to the micturition cycle have been observed in cats [39]. DBS in the STN proved to have an inhibitory effects on the micturition reflex in animals $[39,40]$ and in patients with PD [95-97]. DBS in the STN also increased bladder capacity and facilitated bladder afferent pathways in the brain of PD patients $[98,99]$. 


\section{Bowel Dysfunction in PD}

3.1. Neural Control of Defecation: Enteric Nervous System and Dopamine. The enteric nervous system (ENS) plays the most important role in regulating the peristaltic reflex of the lower gastrointestinal (GI) tract (LGIT) [100]. Slow phasic pressure waves are the most common manometric phenomenon [101], and are measured in the colon and rectum (spontaneous phasic rectal contraction) in humans [102-105]. The origin of the slow wave rhythmicity in LGIT has been identified in the myenteric (Auerbach's) and submucous (Meisner's) plexuses, where interstitial cells of Cajal (ICC) exist [106]. The peristaltic reflex consists of two components: ascending contraction oral to, and descending relaxation caudal to, the site of stimulus (Figure 4 ). The reflex can be evoked by surface stroking or by circumferential stretch [100], in which 5-HT stimulates the sensory nerve terminals [107]. The oral excitatory component is mediated by cholinergic fibers whereas the aboral inhibitory component is mediated by nonadrenergic, noncholinergic fibers. Thus, local neuronal circuits and ICCs, together with appropriate external stimuli, might bring about the peristaltic reflex. Other types of pressure changes in the colon include giant motor complexes [100], which is perhaps analogous to the migrating motor complex of small intestine $[100,101]$. After a meal, the motility index increases for 20 to $30 \mathrm{~min}$ and remains elevated for up to 3 hours. A combination of slow waves and giant motor complexes is thought to promote bowel transport, which is measured by colonic transit time (CTT) in humans $[107,108]$.

The strength of cholinergic transmission in the ENS is thought to be regulated by opposing receptors; serotonin 5HT4 receptor-mediating excitation $[109,110]$ and dopamine D2 receptor-mediating inhibition $[111,112]$. Endogenous 5-HT may facilitate intestinal motility [109], as colorectal motility is greater than normal in 5-HT transporter knockout mice with elevated extracellular 5-HT levels. Reports using dopamine transporter knockout mice have indicated that endogenous dopamine may inhibit intestinal motility $[113,114]$. However, a number of studies have also demonstrated increased motility in the colon (scarce in dopamine receptors) in response to dopamine $[115,116]$, presumably mediated by other receptor populations such as adrenergic or serotonergic receptors, or by central mechanisms [116]. It is uncertain whether MPTP-induced parkinsonian animals might have enteric dopaminergic pathology as seen in $\mathrm{PD}$ [117-121]. Nevertheless, MPTP/salsolinol-induced parkinsonian animals showed decreased GI motility [122] and decreased c-Kit expression in the ICC [123]. More recently, Dorolet and colleagues found myenteric plexus alphasynuclein aggregate pathology, neuron loss, and slowing of gastrointestinal motility in rotenone-induced parkinsonian animals [124].

3.2. Extraenteric Nervous System and Dopamine. Whereas small intestine and ascending colon are innervated by the vagus nerves originating in the medulla, extraenteric innervation of descending colon, sigmoid colon, and rectum primarily shares that of the LUT (Figure 5) [7, 102]. LUT and LGIT perform the similar function of storage and emptying. However, there are also profound differences with regard to physiology (dysfunctional transport, rare ureter versus common bowel; smooth muscle contraction, only on emptying bladder contraction versus persistent spontaneous phasic rectal contraction; abdominal strain, minimum versus large, resp.) [102]. In addition, while the LUT requires intact neuraxis for storage and emptying [7], it has not been entirely clear to what extent LGIT needs extra-ENS.

Acute transection of the pelvic plexus shows slowed transit and abolishes the defecation reflex [125]. Six months later, the transit and defecation reflex are recovered [125]. In contrast, chronic replacement of esophagus [126] or bladder [127] by a colonic segment preserves colonic motility. Pathological studies in PD have shown a degenerative lesion in the spinal parasympathetic PGN [128], although the degree is much less than that in MSA. No Lewy bodies were found in the Onuf's nucleus innervating the anal sphincter [128]. Both the sacral cord and the vagus nuclei receive projecting fibers from Barrington's nucleus (identical to the PMC) in the pons. The spinal descending pathway for defecation is located in the lateral columns in humans [129, 130]. In the acute stage of spinal cord injury [131] or multiple sclerosis [132], CTT is significantly prolonged. In the chronic phase, prolonged CTT of the proximal colon returns to normal whereas that of the distal colon persists $[133,134]$. Abdominal strain and cough are accompanied by sphincter contraction, which is called the guarding reflex [135]. However, when the sphincter contraction is large enough, defecation becomes unsuccessful as commonly seen in spinal cord injury (paradoxical sphincter contraction on defecation (PSCD) or anismus) [136]. In the brainstem, lesion in the vagus nuclei causes intestinal pseudo-obstruction [137, 138]. In PD, neuronal cell loss [139] and the appearance of Lewy bodies [128] in the vagus nuclei have been documented. Barrington's nucleus is thought to be critical to eliciting migrating motor complex [140, 141]. In PD, involvement of the Barrington's nucleus has also been documented [139].

The basal ganglia modulate the bowel motility [142, 143], with the main action apparently being inhibitory [142, 143]. However, under stress conditions, facilitatory responses were also observed $[144,145]$. Although the connection is not fully clarified, bowel function seems to be modulated by the higher brain structures [146]. Most areas activated in functional neuroimaging by bowel distention [147] strikingly overlap the area activated by bladder distention [148].

\subsection{Bowel Dysfunction in PD}

3.3.1. Lower Gastrointestinal Tract Symptoms. In PD there is dysfunction along the entire length of the GI tract. Therefore, while we focus on the colon and rectum, we refer to stomach and small intestine when necessary. The reported prevalence of LGIT symptoms in PD is mostly more than half [149151]. However, it has been difficult to determine the extent to which PD is contributing to the LGIT symptoms. This difficulty occurs because not only PD but also idiopathic constipation may occur in the elderly due in part to dietary 


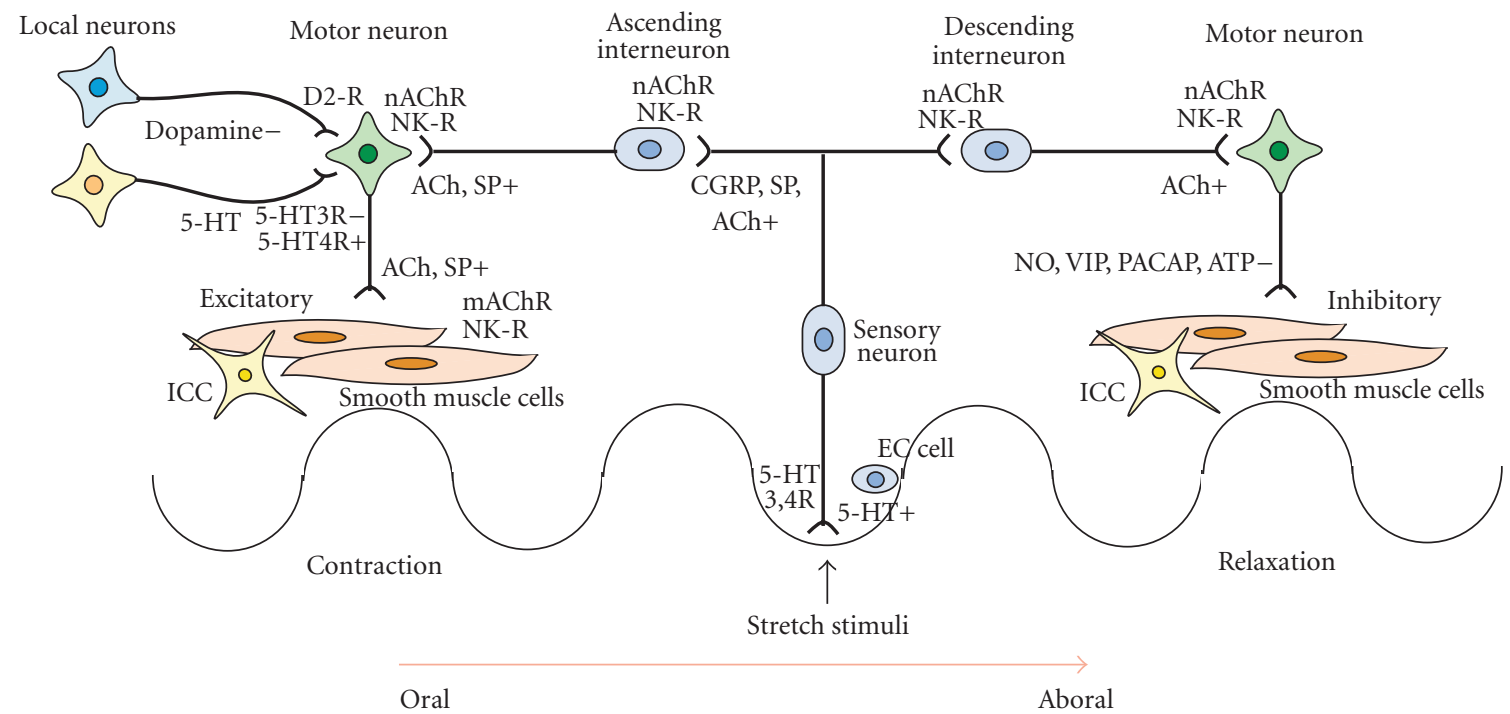

Figure 4: Enteric neural circuitry relevant to peristaltic reflex. Following mucosal stimulation, 5-HT is released from enterochromaffin cells to intrinsic primary sensory neurons (with 5-HT3 and 5-HT4 receptors) and extrinsic vagal and spinal sensory neurons (with 5-HT3 receptors). Sensory neurons release calcitonin gene-regulated peptide (CGRP), substance (SP), and acetylcholine (ACh) to interneurons. Interneurons release ACh and SP orally to excitatory motorneurons while ACh is released aborally to inhibitory motorneurons. Excitatory motorneurons release ACh and SP to smooth muscle cells while inhibitory motorneurons release nitric oxide (NO), vasoactive intestinal peptide (VIP), pituitary adenylate cyclase-activating polypeptide (PACAP), and adenosine triphosphate (ATP) to smooth muscle cells. 5HT also acts as an excitatory modulator on motor neurons (with 5-HT3 and 5-HT4 receptors) whereas dopamine seems to be an inhibitory modulator on motor neurons (with D2 receptor). Interstitial cells of Cajal (ICC) interact with smooth muscle cells for generating rhythmicity (with Ach, VIP, and NO receptors).

habit [151], exercise [152], or age-related ENS degeneration [153]. Controlled studies [5, 149, 154, 155] could overcome these problems, in which the incidence rate of decreased stool frequency $(<3$ times a week) in $\mathrm{PD}$ patients ranges from $20 \%$ to $81 \%$, that of difficulty in stool expulsion in $57-67 \%$, and that of diarrhea in $21 \%$. All of these values are significantly higher than in the normal population (range, decreased stool frequency, 0-33\%; difficulty in stool expulsion, 26-28\%; diarrhea, 10\%) [5, 149, 154, 155]. Fecal incontinence has been reported to be $10-24 \%$ in PD [5, 149]. Therefore, constipation is the most prominent LGIT symptoms in patients with PD. Indeed, PD is a risk factor for elderly nursing home residents to have constipation [156]. Of particular importance is that bowel dysfunction affects the quality of life in patients with PD [5].

There is no significant difference in the use of dopaminergic or anticholinergic drugs and bowel dysfunction [5, 149]. Difficulty in expulsion, and diarrhea are more common in the higher grade of Hoehn and Yahr staging [5, 149, 150], suggesting a relationship between dopaminergic degeneration and LGIT symptoms. However, there are also studies in which no such relationship was found [157]. Constipation in PD occurs commonly with a low coefficient of variation in electrocardiographic $\mathrm{R}$ to $\mathrm{R}$ intervals [158]. The findings indicate that parasympathetic dysfunction might underlie these abnormalities. A recent epidemiological study revealed an association between the frequency of bowel movements and the future risk of developing PD [159]. From a clinical perspective, it is of particular importance that patients with PD see gastroenterologists or physicians first because of their bowel dysfunction before a diagnosis of $\mathrm{PD}$ is made.

A more severe and often acute presentation of bowel dysfunction is intestinal pseudo-obstruction [160], also called paralytic ileus. Yokoyama and Hasegawa [161] have recently reported the frequency to be $7.1 \%$ among 112 patients with PD. Radiographical features of intestinal pseudo-obstruction are dilatation of colon and small intestine [160, 162-164]. True obstruction due to volvulus in PD also occur [161, 163, 164]. Intestinal pseudo-obstruction also occurs insidiously $[165,166]$. In such patients, histology specimens may reveal Lewy body disorder.

3.3.2. Lower Gastrointestinal Tract Function Tests. LGIT function primarily consists of (1) colonic transport of the bowel content to the anorectum $[107,108]$, (2) transient anorectum reservoir, and (3) defecation from the anorectum with the aid of strain [102]. In PD, constipation results primarily from decreased transport and/or disturbed anorectal evacuation. Fecal incontinence may result from disturbed anorectal reservoir, or overflow secondary to constipation.

3.3.3. Transit Time Study. Previous reports have shown that total CTT is increased beyond the normal threshold in $80 \%$ of PD patients [167], which translates into an increased average CTT ranging from 44 hours to 130 hours in PD $[167,168]$, and in 89 hours in de novo PD patients [167], all of which are significantly longer than those of controls 


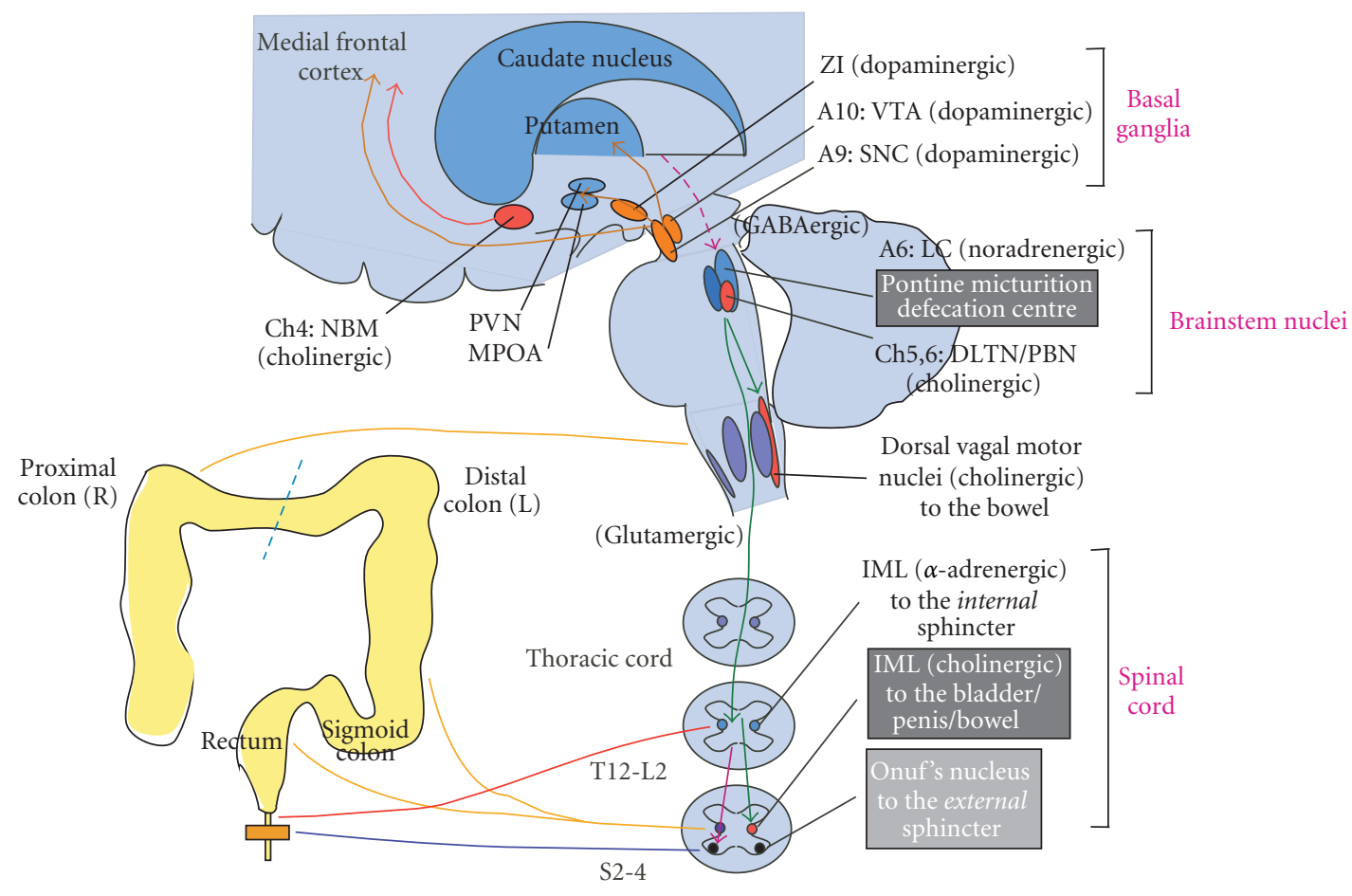

Figure 5: Neural circuitry relevant to defecation. Although less significantly than the lower urinary tract (LUT) does, it is thought that function of the lower gastrointestinal tract depends on the brain and the spinal cord. Whereas small intestine and ascending colon are innervated by the vagus nerves originating in the medulla, descending colon, sigmoid colon, and rectum primarily share sacral innervation of the LUT (Figure 1). Both the sacral cord and the vagus nuclei receive projecting fibers from Barrington's nucleus (the pontine micturition/defecation center). Bowel function seems to be modulated by the higher brain structures; including the frontal lobe, the hypothalamus, and the basal ganglia; the main action of the latter on the bowel seems to be inhibitory. NBM: nucleus basalis Meynert, Ch: cholinergic, PVN: paraventricular nucleus, MPOA: medial preoptic area, ZI: zona incerta, A: adrenergic/noradrenergic, VTA: ventral tegmental area, SNC: substantia nigra pars compacta, LC: locus ceruleus, DLTN: dorsolateral tegmental nucleus, PBN: parabrachial nucleus, PAG: periaqueductal gray, IML: IML cell column, GABA: $\gamma$-aminobutyric acid, T: thoracic, L: lumbar, S: sacral.

(range, 20-39 hours) [160, 167, 168]. Prolonged CTT has also been documented in PD patients without subjective constipation [169]. Slow colonic transit is the major cause of decreased stool frequency. The slow colonic transit is likely to reflect a decrease in slow waves and spike activities of the colon, which may reflect the ENS pathology, and to a lesser extent, the CNS pathology in PD. Among right, left, and rectosigmoid segments of the CTT, the rectosigmoid CTT is significantly prolonged in PD patients $[160,167,169]$. Several explanations for this finding can be hypothesized. It is possible that the ENS innervated by the sacral cord is more severely affected than that innervated by the DMV in PD [160]. Oro-caecal transit time in PD is also prolonged [170].

Pathological studies have demonstrated that PD affects the ENS [117-121]; showing decrease in dopaminergic myenteric neurons and the appearance of Lewy bodies along the proximal-distal axis, for example, they were most frequent in the lower esophagus, but scarce in the rectum. Presumably, degeneration of not only the inhibitory (dopaminergic) fibers, but also of facilitatory (cholinergic and serotonergic) fibers might contribute to the slow colonic transit in PD.

\subsubsection{Rectoanal Videomanometry and Sphincter Electromyography}

Resting State. Anal function at the resting state is measured by anal manometry and analysis of the external sphincter motor unit potentials. At the resting state, the anal pressure of PD patients is low or normal $[160,171]$. The resting anal pressure may reflect sympathetic innervation in the internal anal sphincter, since lesions or anaesthetic blocks at T12-L3 (where the sympathetic PGN is located) substantially lessen the anal pressure [172]. Similarly, PD patients have low [173] or normal $[160,171]$ anal pressure increase on squeezing. However, neurogenic changes in motor unit potentials of the external sphincter muscles occur in only $0-15 \%$ of $\mathrm{PD}$ patients $[174,175]$. This negative finding may correspond to the result of pathological studies indicating that the sacral Onuf's nucleus is spared in the majority of PD patients [128]. Nevertheless, the latent anal sphincter dysfunction may explain the fecal incontinence that occurs in most advanced cases. The rectoanal inhibitory reflex comprises a slow anal pressure decrease following a rapid distention of the intrarectal balloon [176]. This reflex might be appropriate for evacuation. In PD, the threshold of the rectoanal inhibitory 
reflex is reduced $[168,171,177]$ or normal. Although this reflex is thought to be mediated by the intrinsic ENS [178], the exact reflex arc is not entirely clear.

3.3.5. Filling Phase. Rectoanal videomanometry measures functions of the anorectum reservoir and evacuation. During slow rectal filling, PD patients have a slightly but not significantly larger rectal volume at first sensation and a maximum desire to defecate compared with control subjects $[160,171]$. The PD patients had the same rectal compliance as control subjects using the slow-liquid-filling method [102, 160], which is in accordance with the studies using the balloon-inflation method. However, the amplitude of the spontaneous phasic rectal contraction in the PD patients is significantly less than that in control subjects $[102,160]$. The decreased spontaneous phasic rectal contraction may share the same aetiology with the decrease in CTT.

In normal subjects, anal pressure not only varies during the storage phase, but also shows a close relation with spontaneous phasic rectal contraction, for example, when the rectal pressure increases, the anal pressure tends to decrease [102]. The concurrent sphincter relaxation with the spontaneous phasic rectal contraction resembles the rectoanal inhibitory reflex [176]. The concurrent sphincter relaxation might be appropriate for the following evacuation phase [102]. However, in the PD patients, both rectal and anal pressures tend to increase together [160]. This phenomenon during filling resembles the paradoxical sphincter contraction on defecation, as described below.

3.3.6. Defecation Phase. In addition to slow transit constipation, anorectal (outlet type) constipation is a common feature in PD. Indeed, most PD patients could not defecate completely and had postdefecation residuals, the volume of which were significantly larger than those in a control group [160]. During defecation, it has remained a subject of controversy whether true rectal contraction occurs, since abdominal strain is large enough to mask the rectal contraction if present. Only a few studies have measured the differential rectal pressure component [179] and not found rectal contraction on defecation. In recent studies, healthy control subjects had a moderate rectal pressure increase on defecation, for example, the healthy subjects utilized the final wave of spontaneous phasic rectal contractions for defecation [102]. However, rectal contraction on defecation in PD patients is smaller than that in controls [160].

The abdominal straining in PD patients is less than that in control subjects [160]. Straining plays a physiological role in both coughing and defecation, which is achieved by cocontraction of the glottis, diaphragm, and abdominal wall [180]. Straining is associated with activation in brainstem nuclei such as the Kolliker-Fuse nucleus and medullary respiratory neurons [180]. However, PD patients show a less pronounced increase in abdominal pressure on coughing $[160,181]$ and Valsalva maneuver $[160,182]$ before starting rectal filling, and in the defecation phase $[160,182]$, than do control subjects. The mechanism of the impaired straining in PD may include rigidity and reduced contractility of the axial muscles, and a failure of coordinated glottis closure [181]. However, neuronal degeneration in the CNS relevant to straining is yet to be clarified in PD.

During defecation, the anal pressure increase on defecation in patients is significantly larger than that in control subjects, with an increase in the sphincter electromyography (EMG) activity. This finding in PD has been described as paradoxical sphincter contraction on defecation (PSCD), or anismus [118, 160,167, 171, 182, 183]. During fictive defecation (straining), a lack of anal inhibition has also been reported in $65 \%$ of PD patients. Although PSCD can also be seen in patients with idiopathic constipation [184], the frequent occurrence of PSCD in PD suggests that PSCD is a disease-related condition. The frequency of PSCD is almost the same in early and late PD [185], indicating that PSCD is an early defecatory abnormality. Mathers and colleagues [182] consider PSCD a focal dystonia. PSCD also occurs in spinal cord-injured patients [136], suggesting that dysfunction in the suprasacral descending pathway to the external sphincter is a contributing factor. Apomorphine is shown to lessen PSCD [182, 183]. This effect was not antagonized by domperidone, which did not penetrate the $\mathrm{BBB}$, suggesting that the CNS pathology may produce PSCD. Both weak abdominal strain and PSCD seem to be the major causes of difficulty in stool expulsion in PD patients.

\subsection{Treatment of Bowel Dysfunction in PD}

3.4.1. Dietary Fibers. Although it is not certain whether exercise may facilitate bowel habit in PD, in the healthy population, moderate exercise is reported to shorten mouthto-anus transit time [186] and improve overall wellbeing [152]. Water content is an important determinant to make stools normal (70\% water) or hard (40-60\% water) [184]. PD patients are reported to have reduced water intake [187]. Diet and laxatives are the first-line treatment for constipation [188]. Dietary fibers such as psyllium produced an improvement in stool consistency and an increase in stool frequency in healthy population [189] and PD [169, 190]. Polyethylene glycol 3350 [191], or bulking and highly hydrophilic agent polycarbophil [192], improve constipation in PD.

3.4.2. Cholinergic Drugs. A prior report has shown that pyridostigmine bromide, an acetylcholinesterase inhibitor, is effective in the amelioration of constipation in PD [193].

\subsubsection{Dopaminergic Drugs}

Levodopa and Other Dopaminergic Agonists. Dopamine is used as a peripheral vasoactive drug in intensive care units, in which dopamine is shown to reduce gastric migrating motor complex [194]. Dopamine also decreases gastric motility in normal volunteers [195] whereas it increases motility of the duodenum and sigmoid colon. Similarly, dopamine administration increases colonic motor activity in irritable bowel syndrome [196]. Unlike dopamine, levodopa penetrates the BBB [197]. However, it is possible that 
levodopa acts on the ENS and affects bowel function in PD, since levodopa can also be metabolized in the periphery. A modern formula utilizes levodopa in combination with peripheral dopa-decarboxylase inhibitor. This regimen could possibly reduce GI side effects [198]. However, no reports are available to see whether levodopa might change gut function in untreated PD patients. As for somatic sphincter function, levodopa improves voluntary anal squeezing in fluctuating PD patients, which parallels an improvement in gait difficulty from "off" to "on" stage [177]. Apomorphine, a dopaminergic agonist, has also been shown to lessen PSCD [182, 183]. This effect is not antagonized by domperidone, suggesting that apomorphine might act on the CNS dopaminergic pathways.

3.4.4. Dopaminergic Blockers. Dopaminergic blockers (domperidone, etc.) are widely used as GI prokinetics by means of antagonizing dopamine's inhibitory effects on the GI motility, particularly D2 receptor blockade [199]. The pharmacological profiles of the compounds differ in terms of their molecular structure, affinity at D2 receptors, and ability to interact with other receptor systems (5-HT3 and 5-HT4 receptors for metoclopramide; 5-HT4 receptors for levosulpiride). Since domperidone does not cross the BBB, it can be used as GI prokinetics for constipation in PD [200], although the effect of domperidone on constipation is minimal. In contrast, dopaminergic blockers that could penetrate the $\mathrm{BBB}$ (metoclopramide, levosulpiride, etc.) may potentially worsen extrapyramidal motor disorder in PD [199]. Since levodopa is absorbed from the small intestine [201], bowel dysfunction in PD may interfere with levodopa absorption, worsen the motor disorder, or even lead to malignant syndrome [202, 203]. Gastric emptying of an isotope-labeled solid meal becomes significantly faster during domperidone therapy in PD [200]. In addition, domperidone pretreatment causes a mean $12 \%$ increase in peak plasma levodopa concentrations that occurs a mean of 10 min earlier than when levodopa is given alone [202]. Peak plasma levodopa concentrations are reported to be greater on levodopa-domperidone than on levodopa-carbidopa [204].

3.4.5. Serotonergic Drugs. Cisapride, a selective 5-HT 4 receptor agonist, has significantly shortened CTT in PD [205], although after 1 year, only a small effect could be demonstrated [206]. Of particular importance is that cisapride add-on therapy improved the "on-off" phenomenon in advanced PD [203]. However, some reports indicated cisapride's D2 dopaminergic receptor blocking property [207]. Cisapride also blocks $\mathrm{K}^{+}$channels and leads to cardiotoxicity. Mosapride is a novel selective 5-HT 4 receptor agonist that lacks a D2 receptor or $\mathrm{K}^{+}$channel blocking property [208]. Mosapride is shown to ameliorate delayed gastric emptying [209] as well as constipation in PD [210], by shortening of total CTT (particularly the caudal segment), and by augmenting the amplitude in rectal contraction during defecation [210]. Improvement of parkinsonism is more significant with pergolide-mosapride than with pergolide-domperidone [211]. Tegaserod, a selective 5-HT 4 agonist, is also effective in ameliorating constipation in $\mathrm{PD}$ [212].

3.4.6. Other Drugs. Although prior reports have indicated the effectiveness of motilides (erythromycin, etc.) [213], neurotrophin-3 [214] and colchicine [215] on constipation in $\mathrm{PD}$, their use remains limited. Type A botulinum toxin injection into the puborectalis muscle $[216,217]$ and biofeedback [218] ameliorates anismus in PD.

\section{Sexual Dysfunction in PD}

4.1. Neural Control of Erection: Normal Erection in Men. Sexual dysfunction is not uncommon in $\operatorname{PD}[5,219-$ 223]. Studies have shown that sexual dysfunction has great significance in relation to quality-of-life measures. However, the detailed mechanism of sexual dysfunction in PD has not been well known.

The genital organ primarily shares lumbosacral innervation with the lower urinary tract. Erection is a vascular event [224]; occurring secondarily after dilatation of the cavernous helical artery and compression of the cavernous vein to the tunica albuginea [224]. Helical artery dilatation is brought about by activation of cholinergic and nitrergic nerves; this activation facilitates nitric oxide secretion from the vascular endothelium. Ejaculation is brought about by contraction of the vas deferens and the bladder neck, in order to prevent retrograde ejaculation, by activation of adrenergic nerves (Figure 6). Sexual intercourse in healthy men can be divided into 3 phases [225]: (a) desire (libido), (b) excitement and erection, and (c) orgasm, seminal emission from the vas deferens, and ejaculation from the penis. Erection can be further classified into 3 types by the relevant stimulation: (1) psychogenic erection (by audiovisual stimulation), (2) reflexive erection (by somatosensory stimulation), and (3) nocturnal penile tumescence (NPT; associated with rapid eye movement (REM-) sleep). "Morning erection" is considered the last NPT in the nighttime.

4.2. Hypothalamic Neurons and Dopamine in Men. Among the 3 types of erection, reflexive erection requires an intact sacral cord, particularly the intermediolateral (IML) cell columns. Pathology studies have shown that involvement of the IML nucleus is common in MSA, whereas it is uncommon in PD. Therefore, reflexive erection can be affected in patients with MSA. In patients with a supra-sacral spinal cord lesion, reflexive erection might be preserved, whereas psychogenic erection is severely disturbed because of a lesion in the spinal pathways to the sacral cord. Libido and erection are thought to be regulated by the hypothalamus; particularly the medial preoptic area (MPOA) and the paraventricular nucleus (PVN) (Figure 4) [226, 227]. Electrical or chemical stimulation in the MPOA/PVN evoked erection and mating behaviors in experimental animals, both of which were abolished by destruction of these areas. Somatosensory inputs from the genitalia ascend in the anterior spinal cord, and project to the MPOA/PVN via the thalamic nuclei. Erotic visual inputs from the retina are thought to reach the 


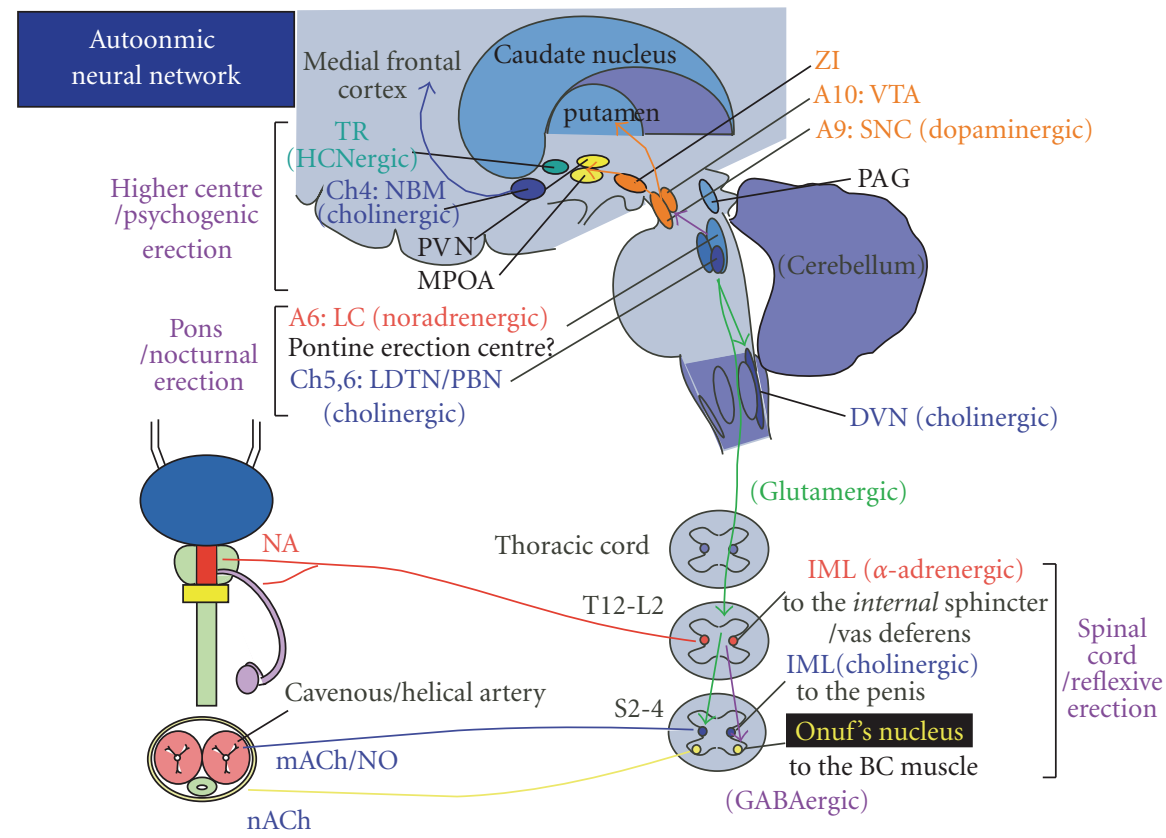

FIGURE 6: Neural circuitry relevant to erection. PAG, periaqueductal gray; LC, locus coeruleus; NBM, nucleus basalis Meynert; PVN, paraventricular nucleus; MPOA, medial preoptic area; A, adrenergic/noradrenergic; ZI, zona incerta; VTA, ventral tegmental area; SNC, substantia nigra pars compacta; DLTN, dorsolateral tegmental nucleus; PBN, parabrachial nucleus; IML, intermediolateral nucleus; GABA, $\gamma$-aminobutyric acid; T, thoracic; L, lumbar; S, sacral; NA, noradrenaline; Ach, acetylcholine; NO, nitric oxide. See text.

MPOA via the mamillary body. Recent neuroimaging studies have shown that penile stimulation or watching pornography activated these areas in humans [228]. NPT [229] seems to be regulated by the hypothalamic lateral preoptic area [230].

The raphe nucleus and the locus ceruleus are candidate areas participating in the regulation of NPT. Oxytocinergic neurons in the hypothalamic PVN are thought to facilitate erection by projecting directly to the sacral cord, and by projecting to the midbrain periaqueductal gray and the Barrington's nucleus (identical to the PMC). Serum oxytocin concentration increases during masturbation in healthy men.

In experimental animals, dopamine is known to facilitate erection and mating behaviors. The MPOA/PVN receives projections from the nigral dopaminergic neurons [231]. A microdialysis study showed that the dopamine concentration in the MPOA was increased by sexual stimulation. It is reported that dopamine D1/D2 receptors in the hypothalamus participate in erection whereas only D2 receptors participate in ejaculation. Pathology studies have shown that the hypothalamus is affected in PD [231]. Recently, polymorphism in the dopamine D4 receptor gene is shown to contribute to individual differences in human sexual behavior [232]. Prolactinergic neurons are thought to be inhibitory in sexual function. Serum prolactin levels increase after orgasm in healthy men. Prolactin-producing pituitary tumors often cause gynecomastia and erectile dysfunction in male patients. Hyperprolactinemia occurs after the use of sulpiride, metoclopramide, and chlorpromazine (all dopamine receptor antagonists). Therefore, dopaminergic neurons seem to facilitate oxytocinergic neurons whereas they inhibit prolactinergic neurons. Some de novo PD patients have hyper prolactinemia [233], which may contribute to erectile dysfunction in those patients.

4.3. Female Sexual Function and Dopamine. As compared with male genitalia, studies of female genital organs are limited. Vulva [234], clitoris [235] and vagina [236] primarily shares lumbosacral innervation with the lower urinary tract. Sexual arousal in women is a vasocongestive and neuromuscular event through these organs, paralleling genital lubrication, controlled by facilitatory parasympathetic (by vasoactive intestinal peptide, nitric oxide, and to a lesser extent acetylcholine, via the pelvic nerves from S2-4 intermediolateral (IML) cell column) and inhibitory sympathetic (by noradrenaline, via the hypogastric nerves from T12L3 IML cell column,) inputs. Some information is thought to travel the vagal nerves. Activity of these spinal nuclei is controlled by sensory afferents from the genitalia and descending projections from the brain.

Like men, libido in women is thought to be regulated by the hypothalamus. The neural circuit for lordosis in animals involves a supraspinal loop, which is controlled by an estrogen- and progesterone-dependent signal, presumably at the ventromedial hypothalamus (VMH), medial preoptic area (MPOA), and paraventricular nucleus (PVN) in the hypothalamus. Lordosis is facilitated by lutenizing hormonereleasing factor (LHRH), alpha-melanocyte stimulating hormone (alpha-MSH), and methionine-enkephalin whereas suppressed by corticotrophin-releasing factor and betaendorphin [237, 238]. Recent neuroimaging studies have shown that vaginal self-stimulation with/without orgasm 
activated these areas in humans [239]. Oxytocinergic neurons in the VMH and the MPOA are thought to facilitate vagino-clitorial sexual arousal and lordosis by projecting directly to the sacral cord $[238,240]$. Role of dopamine in female sexual function remains not completely clear [241]. It is reported that lordosis was increased in female animals by microinjection of apomorphine (D1, 2 agonist) and quinpirole (D2 agonist) in the MPOA whereas it decreased by SKF 38393 (D1 agonist) [242]. This was counteracted by chemical inhibition of dopaminergic neurons in the ventral tegmental area (VTA) [243].

4.3.1. Male Sexual Symptoms. The reported prevalence of sexual symptoms in men with PD ranges from $37 \%$ to 65\% [234-239]. Only few previous studies have looked at sexual symptoms in PD and control subjects. Jacobs et al. [244] studied 121 men with PD (mean age 45 years) and 126 age- and sex-matched community male controls. Patients were more dissatisfied with their present sexual functioning and relationship whereas no differences were found for the frequency of sexual intercourse itself. Erection and ejaculation were not inquired. Sakakibara et al. [5] analyzed sexual function of 46 men with PD (age 35-70 years old) and 258 healthy male control subjects (age 30-70 years old) [5]. As compared with the control group, the frequency of dysfunction in PD patients was significantly higher for decrease of libido (84\%), decrease of sexual intercourse $(55 \%)$, decrease of orgasm $(87 \%)$, and decrease of erection (79\%) and ejaculation (79\%). Therefore, sexual dysfunction is significant in PD. The majority of patients had onset of the sexual dysfunction after the appearance of the motor disorder. This is in contrast to patients with MSA, who often have sexual dysfunction before the onset of motor disorder.

Comparing the results between four age subgroups (subjects in their 30s, 40s, 50s, and 60s) in the control group, the frequencies of sexual intercourse and of orgasm were significantly lower in older individuals [5]. In the PD group, only the frequency of orgasm was lower in older men $(P<0.05)$. Comparing the results between both sexes in the control group, decrease of libido and orgasm were more common in women $(P<0.01)$. In the PD group, there was no significant difference in sexual function items. Bronner et al. [245] reported that use of medications (selective serotonin reuptake inhibitors used for comorbid depression), and advanced PD stage contributed to the development of ED.

4.3.2. Rigiscan. In healthy men, sexual intercourse is thought to be carried out by integrating affective, motor, sensory, autonomic, and other factors. In male patients with PD, depression, motor disorder, and pain inevitably lead to sexual dysfunction. In contrast, it has been difficult to determine to what extent autonomic factors contribute to the sexual dysfunction in PD. However, erectile dysfunction often precedes motor disorder in MSA, and abnormal NPT is not uncommon in PD. These findings strongly suggest that the disorder does in fact contribute to sexual dysfunction in $\mathrm{PD}$. Rigiscan is an objective measure for erectile dysfunction, which allows both tumescence and rigidity measurement, and is suitable for assessing NPT.

Only few data have been available concerning the relationship between NPT and dopamine. However, in experimental animals, administration of levodopa elicited erection and yawning together. Animals with experimental parkinsonism showed fewer REM stages during sleep than control animals did.

4.3.3. Female Sexual Dysfunction. As compared with men, few studies are available concerning female sexual dysfunction in PD. Further, only few previous studies have looked at female sexual symptoms in PD and control subjects. Sakakibara et al. [5] analyzed sexual function of 38 women with PD (age 35-70 years old) and 98 healthy control women (age 30-70 years old) [5]. As compared with the control group, the frequency of dysfunction in women with PD was significantly higher for decrease of libido (83\%) and decrease of sexual intercourse $(88 \%)$ while decrease of orgasm was not different between women with PD and control. The majority of patients had onset of the sexual dysfunction after the appearance of the motor disorder. Welsh et al. [246] studied 27 women with PD (mean age 67 years) and community healthy controls, and in both group $50 \%$ were sexually active. As compared with control, women with PD had more common decrease of libido, vaginal tightness, involuntary urination, and dissatisfaction in sexual intercourse. There was no difference in terms of sexual arousal, sexual intercourse, and orgasm. Without control, in young PD patients (36-56 years) women had more common sexual problems (decrease of libido, 70\%, decrease of sexual intercourse, $80 \%)$ than men $(40 \%, 33.4 \%$, resp.) $[247,248]$. Other domains, such as loss of lubrication and pain, are not clearly known.

\subsection{Treatment of Sexual Dysfunction in PD}

\subsubsection{Male Sexual Dysfunction}

Dopaminergic Drugs. It is possible that levodopa and other antiparkinson medication may affect sexual function in PD. However, it is not entirely clear to what extent levodopa ameliorates sexual dysfunction in PD. In contrast, subcutaneous apomorphine injection is used to ameliorate fluctuating symptoms in PD. It has also been used to treat erectile dysfunction in the general population [247, 248] and in patients with PD [249], although the dose is different (general population, initial $2 \mathrm{mg}$ and up to $3 \mathrm{mg}$ [247, 248], PD, $4 \mathrm{mg}$ [250]). Apomorphine is thought to stimulate dopamine D2 receptors, and activate oxytocinergic neurons in the PVN. Nausea is a common side effect of this drug. Cabergoline [251] and pergolide [252] are also reported to improve sexual dysfunction in PD. In contrast, pathological hypersexuality may occur together with [253] or without delirium [254], which is attributed to the dopamine dysregulation syndrome in this disorder. DBS in the STN has produced either improved sexual wellbeing [255] or transient mania with hypersexuality [256] in patients with $\mathrm{PD}$. 
Phosphodiesterase-5 Inhibitors. When dopaminergic drugs did not help, phosphodiesterase-5 inhibitors, for example, sildenafil, vardenafil, and so forth, become the first line treatment in PD [257, 258]. These drugs inhibit nitric oxide degradation and facilitate smooth muscle relaxation in the cavernous tissue. When treating PD patients with postural hypotension, these drugs should be prescribed with extreme caution [258].

Other Drugs. When phosphodiesterase- 5 inhibitors did not help, recent trials of melanocortin, for example, melanotanII, bremelanotide, and so forth, showed that these drugs might become a choice for treating erectile dysfunction. A group of pro-opio-melanocortin (POMC) gene products include adrenocorticotropic hormone (ACTH), $\alpha$ melanocyte stimulating hormone $(\alpha-\mathrm{MSH}), \beta$-MSH, and $\gamma$ MSH. It is known that the arcuate nucleus of the hypothalamus projects POMC-containing neurons to the lateral hypothalamus, dorsal medial nucleus, MPOA, and PVN [22]. $\alpha$-MSH as secreted in the MPOA and PVN participates in the central control of sexual function [21]. Bremelanotide is a melanocortin receptor agonist, and is reported to be effective for treating erectile dysfunction as compared with placebo [259].

4.4.2. Female Sexual Dysfunction. There is no established regimen to treat sexual dysfunction in women with PD. PDE5 inhibitors, such as sildenafil, tadalafil, and vardenafil, has become the first choice in the treatment of erectile dysfunction in men. Whereas sildenafil facilitated clitorial engorgement in women with sexual dysfunction [260], clinical efficacy of this drug in women with PD awaits further clarification [261]. Bremelanotide, a melanocortin receptor agonist, is applied to female sexual dysfunction, and is reported to be effective [262].

\section{Conclusions}

This article reviewed the current concepts of bladder, bowel, and sexual dysfunction (pelvic organ dysfunctions) in PD. Central nervous system pathology is clearly associated with bladder (urinary urgency/frequency) and sexual dysfunction (decrease in libido, erection, and overall dissatisfaction) in PD. In contrast, both central (weak strain and anismus) and peripheral myenteric pathology (slow colonic transit and loss of rectal contraction) are associated with bowel dysfunction. Anticholinergic agents are generally used to treat bladder dysfunction while phosphodiesterase inhibitors are used to treat sexual dysfunction. Dietary fibers, laxatives, and serotonergic agents are used to treat bowel dysfunction. These treatments are beneficial in maximizing patients' quality of life.

\section{References}

[1] K. R. Chaudhuri, D. G. Healy, and A. H. V. Schapira, "Non-motor symptoms of Parkinson's disease: diagnosis and management," The Lancet Neurology, vol. 5, no. 3, pp. 235245, 2006.

[2] R. Sakakibara, T. Uchiyama, T. Yamanishi, K. Shirai, and T. Hattori, "Bladder and bowel dysfunction in Parkinson's disease," Journal of Neural Transmission, vol. 115, no. 3, pp. 443-460, 2008.

[3] C. Magerkurth, R. Schnitzer, and S. Braune, "Symptoms of autonomic failure in Parkinson's disease: prevalence and impact on daily life," Clinical Autonomic Research, vol. 15, no. 2, pp. 76-82, 2005.

[4] C. W. McGrother, C. Jagger, M. Clarke, and C. M. Castleden, "Handicaps associated with incontinence: implications for management," Journal of Epidemiology and Community Health, vol. 44, no. 3, pp. 246-248, 1990.

[5] R. Sakakibara, H. Shinotoh, T. Uchiyama et al., "Questionnaire-based assessment of pelvic organ dysfunction in Parkinson's disease," Autonomic Neuroscience: Basic and Clinical, vol. 92, no. 1-2, pp. 76-85, 2001.

[6] T. Uchiyama, R. Sakakibara, T. Hattori, and T. Yamanishi, "Short-term effect of a single levodopa dose on micturition disturbance in Parkinson's disease patients with the wearingoff phenomenon," Movement Disorders, vol. 18, no. 5, pp. 573-578, 2003.

[7] W. C. de Groat, "Integrative control of the lower urinary tract: preclinical perspective," British Journal of Pharmacology, vol. 147, no. 2, pp. S25-S40, 2006.

[8] R. Sakakibara and C. J. Fowler, "Brain disease," in Neurologic Bladder, Bowel, and Sexual Function, C. J. Fowler, Ed., vol. 1 of WFN Seminars in Clinical Neurology, chapter 9, pp. 98-109, Elsevier, Boston, Mass, USA, 2001.

[9] R. Sakakibara, M. Mori, T. Fukutake, K. Kita, and T. Hattori, "Orthostatic hypotension in a case with multiple sclerosis," Clinical Autonomic Research, vol. 7, no. 3, pp. 163-165, 1997.

[10] P. Abrams, L. Cardozo, M. Fall et al., "The standardisation of terminology of lower urinary tract function: report from the standardisation sub-committee of the International Continence Society," Neurourology and Urodynamics, vol. 21, no. 2, pp. 167-178, 2002.

[11] B. F. M. Blok and G. Holstege, "The central control of micturition and continence: implications for urology," BJU International, vol. 83, supplement 2, pp. 1-6, 1999.

[12] R. Sakakibara, K. Nakazawa, K. Shiba et al., "Firing patterns of micturition-related neurons in the pontine storage centre in cats," Autonomic Neuroscience: Basic and Clinical, vol. 99, no. 1, pp. 24-30, 2002.

[13] R. B. C. Kavia, R. Dasgupta, and C. J. Fowler, "Functional imaging and the central control of the bladder," Journal of Comparative Neurology, vol. 493, no. 1, pp. 27-32, 2005.

[14] R. Sakakibara, T. Hattori, K. Yasuda, T. Yamanishi, M. Tojo, and M. Mori, "Micturitional disturbance in Wernicke's encephalopathy," Neurourology and Urodynamics, vol. 16, no. 2, pp. 111-115, 1997.

[15] S. Matsuura, G. V. Allen, and J. W. Downie, "Volumeevoked micturition reflex is mediated by the ventrolateral periaqueductal gray in anesthetized rats," American Journal of Physiology, vol. 275, no. 6, pp. R2049-R2055, 1998.

[16] Z. Liu, R. Sakakibara, K. Nakazawa et al., "Micturitionrelated neuronal firing in the periaqueductal gray area in cats," Neuroscience, vol. 126, no. 4, pp. 1075-1082, 2004.

[17] H. Yaguchi, H. Soma, Y. Miyazaki et al., "A case of acute urinary retention caused by periaqueductal grey lesion," Journal of Neurology, Neurosurgery and Psychiatry, vol. 75, no. 8, pp. 1202-1203, 2004. 
[18] C. D. Betts, R. Kapoor, and C. J. Fowler, "Pontine pathology and voiding dysfunction," British Journal of Urology, vol. 70, no. 1, pp. 100-102, 1992.

[19] R. Sakakibara, T. Hattori, K. Yasuda, and T. Yamanishi, "Micturitional disturbance and the pontine tegmental lesion: urodynamic and MRI analyses of vascular cases," Journal of the Neurological Sciences, vol. 141, no. 1-2, pp. 105-110, 1996.

[20] M. Sasaki, "Role of Barrington's nucleus in micturition," Journal of Comparative Neurology, vol. 493, no. 1, pp. 21-26, 2005.

[21] G. Matsumto, T. Hisamitsu, and W. C. de Groat, "Role of glutamate and NMDA receptors in the descending limb of the spinobulbospinal micturition reflex pathway of the rat," Neuroscience Letters, vol. 183, no. 1-2, pp. 58-61, 1995.

[22] B. F. M. Blok, H. de Weerd, and G. Holstege, "The pontine micturition center projects to sacral cord GABA immunoreactive neurons in the cat," Neuroscience Letters, vol. 233, no. 2-3, pp. 109-112, 1997.

[23] C. J. Fowler, "Integrated control of lower urinary tract: clinical perspective," British Journal of Pharmacology, vol. 147, no. 2, pp. S14-S24, 2006.

[24] W. D. Steers, "Pathophysiology of overactive and urge urinary incontinence," Reviews in Urology, vol. 4, supplement 4, pp. S7-S18, 2002.

[25] K. E. Andersson, "Mechanisms of disease: central nervous system involvement in overactive bladder syndrome," Nature Clinical Practice Urology, vol. 1, no. 2, pp. 103-108, 2004.

[26] O. Yokoyama, S. Yotsuyanagi, H. Akino, N. Moriyama, Y. Matsuta, and M. Namiki, "RNA synthesis in the pons necessary for maintenance of bladder overactivity after cerebral infarction in the rat," Journal of Urology, vol. 169, no. 5, pp. 1878-1884, 2003.

[27] O. Yokoyama, M. Yoshiyama, M. Namiki, and W. C. de Groat, "Changes in dopaminergic and glutamatergic excitatory mechanisms of micturition reflex after middle cerebral artery occlusion in conscious rats," Experimental Neurology, vol. 173, no. 1, pp. 129-135, 2002.

[28] S. Seki, Y. Igawa, K. Kaidoh, O. Ishizuka, O. Nishizawa, and K. E. Andersson, "Role of dopamine D1 and D2 receptors in the micturition reflex in conscious rats," Neurourology and Urodynamics, vol. 20, no. 1, pp. 105-113, 2001.

[29] N. Yoshimura, S. Kuno, M. B. Chancellor, W. C. de Groat, and S. Seki, "Dopaminergic mechanisms underlying bladder hyperactivity in rats with a unilateral 6-hydroxydopamine (6OHDA) lesion of the nigrostriatal pathway," British Journal of Pharmacology, vol. 139, no. 8, pp. 1425-1432, 2003.

[30] N. Yoshimura, E. Mizuta, O. Yoshida, and S. Kuno, “Therapeutic effects of dopamine D1/D2 receptor agonists on detrusor hyperreflexia in 1-methyl-4-phenyl-1,2,3,6-tetrahydropyridine-lesioned parkinsonian cynomolgus monkeys," Journal of Pharmacology and Experimental Therapeutics, vol. 286, no. 1, pp. 228-233, 1998.

[31] S. Nour, C. Svarer, J. K. I. Kristensen, O. B. Paulson, and I. Law, "Cerebral activation during micturition in normal men," Brain, vol. 123, no. 4, pp. 781-789, 2000.

[32] T. Kitta, H. Kakizaki, T. Furuno et al., "Brain activation during detrusor overactivity in patients with Parkinson's disease: a positron emission tomography study," Journal of Urology, vol. 175, no. 3, pp. 994-998, 2006.

[33] R. Sakakibara, H. Shinotoh, T. Uchiyama, M. Yoshiyama, T. Hattori, and T. Yamanishi, "SPECT imaging of the dopamine transporter with $\left[{ }^{123} \mathrm{I}\right]-\beta$-CIT reveals marked decline of nigrostriatal dopaminergic function in Parkinson's disease with urinary dysfunction," Journal of the Neurological Sciences, vol. 187, no. 1-2, pp. 55-59, 2001.

[34] K. Winge, L. Friberg, L. Werdelin, K. K. Nielsen, and H. Stimpel, "Relationship between nigrostriatal dopaminergic degeneration, urinary symptoms, and bladder control in Parkinson's disease," European Journal of Neurology, vol. 12, no. 11, pp. 842-850, 2005.

[35] N. Yoshimura, M. Sasa, O. Yoshida, and S. Takaori, "Dopamine D-1 receptor-mediated inhibition of micturition reflex by central dopamine from the substantia nigra," Neurourology and Urodynamics, vol. 11, no. 5, pp. 535-545, 1992.

[36] R. Sakakibara, K. Nakazawa, T. Uchiyama, M. Yoshiyama, T. Yamanishi, and T. Hattori, "Micturition-related electrophysiological properties in the substantia nigra pars compacta and the ventral tegmental area in cats," Autonomic Neuroscience: basic and Clinical, vol. 102, no. 1-2, pp. 30-38, 2002.

[37] T. Yamamoto, R. Sakakibara, K. Hashimoto et al., "Striatal dopamine level increases in the urinary storage phase in cats: an in vivo microdialysis study," Neuroscience, vol. 135, no. 1, pp. 299-303, 2005.

[38] Y. Smith, M. D. Bevan, E. Shink, and J. P. Bolam, "Microcircuitry of the direct and indirect pathways of the basal ganglia," Neuroscience, vol. 86, no. 2, pp. 353-387, 1998.

[39] R. Sakakibara, K. Nakazawa, T. Uchiyama, M. Yoshiyama, T. Yamanishi, and T. Hattori, "Effects of subthalamic nucleus stimulation on the micturation reflex in cats," Neuroscience, vol. 120 , no. 3, pp. 871-875, 2003.

[40] A. L. Dalmose, C. R. Bjarkam, J. C. Sorensen, J. C. Djurhuus, and T. M. Jorgensen, "Effects of high frequency deep brain stimulation on urine storage and voiding function in conscious minipigs," Neurourology and Urodynamics, vol. 23, no. 3, pp. 265-272, 2004.

[41] K. Hashimoto, T. Oyama, Y. Ukay et al., "Selective destruction of dopamine neurones of the ventral tegmental area, but not the substantia nigra, impairs reflex micturition in rats," Neurourology and Urodynamics, vol. 16, pp. 470-471, 1997.

[42] K. Hashimoto, T. Oyama, T. Sugiyama, Y. C. Park, and T. Kurita, "Neuronal excitation in the ventral tegmental area modulates the micturition reflex mediated via the dopamine D1 and D2 receptors in rats," Journal of Pharmacological Sciences, vol. 92, no. 2, pp. 143-148, 2003.

[43] G. F. Murnaghan, "Neurogenic disorders of the bladder in Parkinsonism," British Journal of Urology, vol. 33, pp. 403409, 1961.

[44] T. Hattori, K. Yasuda, K. Kita, and K. Hirayama, "Voiding dysfunction in Parkinson's disease," Japanese Journal of Psychiatry and Neurology, vol. 46, no. 1, pp. 181-186, 1992.

[45] R. Gray, G. Stern, and J. Malone-Lee, "Lower urinary tract dysfunction in Parkinson's disease: changes relate to age and not disease," Age and Ageing, vol. 24, no. 6, pp. 499-504, 1995.

[46] T. Hald and B. We, The Urinary Bladder, Neurology and Dynamics, Williams and Wilkins, Baltimore, Md, USA, 1982.

[47] J. T. Andersen, "Disturbances of bladder and urethral function in Parkinson's disease," International Urology and Nephrology, vol. 17, no. 1, pp. 35-41, 1985.

[48] Y. Berger, J. G. Blaivas, E. R. DeLaRocha, and J. M. Salinas, "Urodynamic findings in Parkinson's disease," Journal of Urology, vol. 138, no. 4, pp. 836-838, 1987.

[49] R. Sakakibara, T. Hattori, T. Uchiyama, and T. Yamanishi, "Urinary function in elderly people with and without leukoaraiosis: relation to cognitive and gait function," Journal of Neurology, Neurosurgery and Psychiatry, vol. 67, no. 5, pp. 658-660, 1999. 
[50] S. Gilman, P. A. Low, N. Quinn et al., "Consensus statement on the diagnosis of multiple system atrophy," Journal of the Autonomic Nervous System, vol. 74, no. 2-3, pp. 189-192, 1998.

[51] I. Araki and S. Kuno, "Assessment of voiding dysfunction in Parkinson's disease by the international prostate symptom score," Journal of Neurology, Neurosurgery and Psychiatry, vol. 68, no. 4, pp. 429-433, 2000.

[52] G. E. Lemack, R. B. Dewey, C. G. Roehrborn, P. E. O'Suilleabhain, and P. E. Zimmern, "Questionnaire-based assessment of bladder dysfunction in patients with mild to moderate Parkinson's disease," Urology, vol. 56, no. 2, pp. 250-254, 2000.

[53] R. N. Campos-Sousa, E. Quagliato, B. B. da Silva, R. M. de Carvalho Jr., S. C. Ribeiro, and D. F. de Carvalho, "Urinary symptoms in Parkinson's disease: prevalence and associated factors," Arquivos de Neuro-Psiquiatria, vol. 61, no. 2, pp. 359-363, 2003.

[54] I. Araki, M. Kitahara, T. Oida, and S. Kuno, "Voiding dysfunction and Parkinson's disease: urodynamic abnormalities and urinary symptoms," Journal of Urology, vol. 164, no. 5, pp. 1640-1643, 2000.

[55] F. Stocchi, A. Carbone, M. Inghilleri et al., "Urodynamic and neurophysiological evaluation in Parkinson's disease and multiple system atrophy," Journal of Neurology, Neurosurgery and Psychiatry, vol. 62, no. 5, pp. 507-511, 1997.

[56] R. Sakakibara, T. Hattori, T. Uchiyama, and T. Yamanishi, "Videourodynamic and sphincter motor unit potential analyses in Parkinson's disease and multiple system atrophy," Journal of Neurology, Neurosurgery and Psychiatry, vol. 71, no. 5, pp. 600-606, 2001.

[57] A. J. Pavlakis, M. B. Siroky, I. Goldstein, and R. J. Krane, "Neurourologic findings in Parkinson's disease," Journal of Urology, vol. 129, no. 1, pp. 80-83, 1983.

[58] H. Fitzmaurice, C. J. Fowler, D. Rickards et al., "Micturition disturbance in Parkinson's disease," British Journal of Urology, vol. 57, no. 6, pp. 652-656, 1985.

[59] T. Uchiyama, R. Sakakibara, and T. Hattori, "Lower urinary tract dysfunctions of Parkinson's disease model rat (6hydroxydopamine treated rat) and effects of drugs," Autonomic Nervous System, vol. 43, no. 4, pp. 302-308, 2006 (Japanese).

[60] D. Griffiths, "Basics of pressure-flow studies," World Journal of Urology, vol. 13, no. 1, pp. 30-33, 1995.

[61] T. Yamamoto, R. Sakakibara, T. Uchiyama et al., "Neurological diseases that cause detrusor hyperactivity with impaired contractile function," Neurourology and Urodynamics, vol. 25, no. 4, pp. 356-360, 2006.

[62] A. J. Pavlakis, M. B. Siroky, I. Goldstein, and R. J. Krane, "Neurourologic findings in Parkinson's disease," Journal of Urology, vol. 129, no. 1, pp. 80-83, 1983.

[63] V. A. Chandiramani, J. Palacej, and C. J. Fowlerj, "How to recognize patients with parkinsonism who should not have urological surgery," British Journal of Urology, vol. 80, no. 1, pp. 100-104, 1997.

[64] I. G. McKeith, D. W. Dickson, J. Lowe et al., "Diagnosis and management of dementia with Lewy bodies: third report of the DLB consortium," Neurology, vol. 65, no. 12, pp. 1863$1872,2005$.

[65] R. Sakakibara, T. Ito, T. Uchiyama et al., "Lower urinary tract function in dementia of Lewy body type," Journal of Neurology, Neurosurgery and Psychiatry, vol. 76, no. 5, pp. 729-732, 2005.
[66] B. Aranda and P. Cramer, "Effects of apomorphine and Ldopa on the parkinsonian bladder," Neurourology and Urodynamics, vol. 12, no. 3, pp. 203-209, 1993.

[67] R. Sakakibara, T. Uchiyama, T. Hattori, and T. Yamanishi, "Urodynamic evaluation in Parkinson's disease before and after levodopa treatment," in Proceedings of the 9th International Catechecholamine Symposium, Kyoto, Japan, 2001.

[68] S. Kuno, E. Mizuta, S. Yamasaki, and I. Araki, "Effects of pergolide on nocturia in Parkinson's disease: three female cases selected from over 400 patients," Parkinsonism and Related Disorders, vol. 10, no. 3, pp. 181-187, 2004.

[69] M. Yamamoto, "Pergolide improves neurogenic bladder in patients with Parkinson's disease," Movement Disorders, vol. 12, p. 328, 1997.

[70] G. S. Benson, D. M. Raezer, J. R. Anderson, C. D. Saunders, and J. N. Corrierie Jr., "Effect of levodopa on urinary bladder," Urology, vol. 7, no. 1, pp. 24-28, 1976.

[71] T. J. Christmas, C. R. Chapple, A. J. Lees et al., "Role of subcutaneous apomorphine in parkinsonian voiding dysfunction," The Lancet, vol. 2, no. 8626-8627, pp. 1451-1453, 1988.

[72] H. Fitzmaurice, C. J. Fowler, D. Rickards et al., "Micturition disturbance in Parkinson's disease," British Journal of Urology, vol. 57, no. 6, pp. 652-656, 1985.

[73] K. Winge, L. M. Werdelin, K. K. Nielsen, and H. Stimpel, "Effects of dopaminergic treatment on bladder function in Parkinson's disease," Neurourology and Urodynamics, vol. 23, no. 7, pp. 689-696, 2004.

[74] L. Brusa, F. Petta, A. Pisani et al., "Central acute D2 stimulation worsens bladder function in patients with mild Parkinson's disease," Journal of Urology, vol. 175, no. 1, pp. 202-206, 2006.

[75] O. Ishizuka, Y. Igawa, O. Nishizawa, and K. E. Andersson, "Role of supraspinal tachykinins for volume-and L-dopainduced bladder activity in normal conscious rats," Neurourology and Urodynamics, vol. 19, no. 1, pp. 101-109, 2000.

[76] J. R. Cooper, F. E. Bloom, and R. H. Roth, The Biochemical Basis of Neuropharmacology, chapter 9, Oxford University Press, Oxford, UK, 8th edition, 2003.

[77] J. A. Obeso, C. W. Olanow, and J. G. Nutt, "Levodopa motor complications in Parkinson's disease," Trends in Neurosciences, vol. 23, no. 10, pp. S2-S7, 2000.

[78] W. R. G. Gibb, A. J. Lees, P. Jenner, and C. D. Marsden, "The dopamine neurotoxin 1-methyl-4-phenyl-1,2,3,6-tetrahydropyridine (MPTP) produces histological lesions in the hypothalamus of the common marmoset," Neuroscience Letters, vol. 65, no. 1, pp. 79-83, 1986.

[79] S. Clemens, D. Rye, and S. Hochman, "Restless legs syndrome: revisiting the dopamine hypothesis from the spinal cord perspective," Neurology, vol. 67, no. 1, pp. 125-130, 2006.

[80] O. Ishizuka, H. Mizusawa, and O. Nishizawa, "Roles of dopaminergic receptors in bladder and erectile function at the spinal level," Asian Journal of Andrology, vol. 4, no. 4, pp. 287290, 2002.

[81] M. M. El-Mas, A. I. Elmallah, A. G. Omar, and F. Sharabi, "Dopamine modulates peripheral purinergic neurotransmission through multiple presynaptic receptors: tissuedependent effects," Pharmacological Research, vol. 39, no. 1, pp. 11-19, 1999.

[82] A. J. Wein and R. R. Rackley, "Overactive bladder: a better understanding of pathophysiology, diagnosis and management," Journal of Urology, vol. 175, no. 3, pp. S5-S10, 2006.

[83] P. Abrams, K. E. Andersson, J. J. Buccafusco et al., "Muscarinic receptors: their distribution and function in body 
systems, and the implications for treating overactive bladder," British Journal of Pharmacology, vol. 148, no. 5, pp. 565-578, 2006.

[84] A. Todorova, B. Vonderheid-Guth, and W. Dimpfel, "Effects of tolterodine, trospium chloride, and oxybutynin on the central nervous system," Journal of Clinical Pharmacology, vol. 41, no. 6, pp. 636-644, 2001.

[85] G. G. Kay, M. B. Abou-Donia, W. S. Messer, D. G. Murphy, J. W. Tsao, and J. G. Ouslander, "Antimuscarinic drugs for overactive bladder and their potential effects on cognitive function in older patients," Journal of the American Geriatrics Society, vol. 53, no. 12, pp. 2195-2201, 2005.

[86] R. Scheife and M. Takeda, "Central nervous system safety of anticholinergic drugs for the treatment of overactive bladder in the elderly," Clinical Therapeutics, vol. 27, no. 2, pp. 144153, 2005.

[87] K. E. Andersson, "Treatment of overactive bladder: other drug mechanisms," Urology, vol. 55, no. 5, pp. 51-57, 2000.

[88] T. Ito, R. Sakakibara, K. Nakazawa et al., "Effects of electrical stimulation of the raphe area on the micturition reflex in cats," Neuroscience, vol. 142, no. 4, pp. 1273-1280, 2006.

[89] G. M. Halliday, P. C. Blumbergs, R. G. H. Cotton, W. W. Blessing, and L. B. Geffen, "Loss of brainstem serotoninand substance P-containing neurons in Parkinson's disease," Brain Research, vol. 510, no. 1, pp. 104-107, 1990.

[90] R. Sakakibara, T. Ito, T. Uchiyama, Y. Awa, C. Yamaguchi, and T. Hattori, "Effects of milnacipran and paroxetine on overactive bladder due to neurologic diseases: a urodynamic assessment," Urologia Internationalis, vol. 81, no. 3, pp. 335339, 2008.

[91] T. Hineno, M. Mizobuchi, K. Hiratani, Y. Inami, and Y. Kakimoto, "Disappearance of circadian rhythms in Parkinson's disease model induced by 1-methyl-4-phenyl-1,2,3,6tetrahydropyridine in dogs," Brain Research, vol. 580, no. 1-2, pp. 92-99, 1992.

[92] O. Suchowersky, S. Furtado, and G. Rohs, "Beneficial effect of intranasal desmopressin for nocturnal polyuria in Parkinson's disease," Movement Disorders, vol. 10, no. 3, pp. 337340, 1995.

[93] Y. Smith, M. D. Bevan, E. Shink, and J. P. Bolam, "Microcircuitry of the direct and indirect pathways of the basal ganglia," Neuroscience, vol. 86, no. 2, pp. 353-387, 1998.

[94] J. O. Dostrovsky and A. M. Lozano, "Mechanisms of deep brain stimulation," Movement Disorders, vol. 17, no. 3, pp. S63-S68, 2002.

[95] E. Finazzi-Agrò, A. Peppe, A. d'Amico et al., "Effects of subthalamic nucleus stimulation on urodynamic findings in patients with Parkinson's disease," Journal of Urology, vol. 169, no. 4, pp. 1388-1391, 2003.

[96] C. Seif, J. Herzog, C. van der Horst et al., "Effect of subthalamic deep brain stimulation on the function of the urinary bladder," Annals of Neurology, vol. 55, no. 1, pp. 118120, 2004.

[97] K. Winge, K. K. Nielsen, H. Stimpel, A. Lokkegaard, S. R. Jensen, and L. Werdelin, "Lower urinary tract symptoms and bladder control in advanced Parkinson's disease: effects of deep brain stimulation in the subthalamic nucleus," Movement Disorders, vol. 22, no. 2, pp. 220-225, 2007.

[98] J. Herzog, P. H. Weiss, A. Assmus et al., "Subthalamic stimulation modulates cortical control of urinary bladder in Parkinson's disease," Brain, vol. 129, no. 12, pp. 3366-3375, 2006.

[99] J. Herzog, P. H. Weiss, A. Assmus et al., "Improved sensory gating of urinary bladder afferents in Parkinson's disease following subthalamic stimulation," Brain, vol. 131, no. 1, pp. 132-145, 2008.

[100] M. B. Hansen, "Neurohumoral control of gastrointestinal motility," Physiological Research, vol. 52, no. 1, pp. 1-30, 2003.

[101] J. E. Kellow, M. Delvaux, F. Azpiroz, M. Camilleri, E. M. M. Quigley, and D. G. Thompson, "Principles of applied neurogastroenterology: physiology/motility-sensation," Gut, vol. 45, no. 2, pp. 17-24, 1999.

[102] T. Ito, R. Sakakibara, T. Uchiyama, L. Zhi, T. Yamamoto, and T. Hattori, "Videomanometry of the pelvic organs: a comparison of the normal lower urinary and gastrointestinal tracts," International Journal of Urology, vol. 13, no. 1, pp. 2935, 2006.

[103] N. W. Read, W. G. Haynes, D. C. C. Bartolo et al., "Use of anorectal manometry during rectal infusion of saline to investigate sphincter function in incontinent patients," Gastroenterology, vol. 85, pp. 105-113, 1983.

[104] A. C. Thorpe, J. P. Roberts, N. S. Williams, J. P. Blandy, and D. F. Badenoch, "Pelvic floor physiology in women with faecal incontinence and urinary symptoms," British Journal of Surgery, vol. 82, no. 2, pp. 173-176, 1995.

[105] P. Broens, D. Vanbeckevoort, E. Bellon, and F. Penninckx, "Combined radiologic and manometric study of rectal filling sensation," Diseases of the Colon and Rectum, vol. 45, no. 8, pp. 1016-1022, 2002.

[106] P. Amborova, P. Hubka, I. Ulkova, and I. Hulin, "The pacemaker activity of interstitial cells of cajal and gastric electrical activity," Physiological Research, vol. 52, no. 3, pp. 275-284, 2003.

[107] D. Couturier and S. Chaussade, "Total and segmental colonic transit times: measurement by radio-opaque markers," Presse Medicale, vol. 17, no. 2, pp. 69-73, 1988.

[108] G. Bassotti, G. de Roberto, D. Castellani, L. Sediari, and A. Morelli, "Normal aspects of colorectal motility and abnormalities in slow transit constipation," World Journal of Gastroenterology, vol. 11, no. 18, pp. 2691-2696, 2005.

[109] M. T. Liu, S. Rayport, L. Jiang, D. L. Murphy, and M. D. Gershon, "Expression and function of 5-HT3 receptors in the enteric neurons of mice lacking the serotonin transporter," American Journal of Physiology, vol. 283, no. 6, pp. G1398G1411, 2002.

[110] M. Tonini, "5-hydroxytryptamine effects in the gut: the 3, 4, and 7 receptors," Neurogastroenterology and Motility, vol. 17, no. 5, pp. 637-642, 2005.

[111] J. K. Walker, R. R. Gainetdinov, A. W. Mangel, M. G. Caron, and M. A. Shetzline, "Mice lacking the dopamine transporter display altered regulation of distal colonic motility," American Journal of Physiology, vol. 279, no. 2, pp. G311-G318, 2000.

[112] M. Anlauf, M. K. H. Schafer, L. Eiden, and E. Weihe, "Chemical coding of the human GI nervous system: cholinergic, VIPergic, and catecholaminergic phenotypes," Journal of Comparative Neurology, vol. 459, no. 1, pp. 90-111, 2003.

[113] R. R. Gainetdinov, S. R. Jones, F. Fumagalli, R. M. Wightman, and M. G. Caron, "Re-evaluation of the role of the dopamine transporter in dopamine system homeostasis," Brain Research Reviews, vol. 26, no. 2-3, pp. 148-153, 1998.

[114] S. L. Zhi, C. Schmauss, A. Cuenca, E. Ratcliffe, and M. D. Gershon, "Physiological modulation of intestinal motility by enteric dopaminergic neurons and the D2 receptor: analysis of dopamine receptor expression, location, development, and function in wild-type and knock-out mice," Journal of Neuroscience, vol. 26, no. 10, pp. 2798-2807, 2006. 
[115] J. Wiley and C. Owyang, "Dopaminergic modulation of rectosigmoid motility: action of domperidone," Journal of Pharmacology and Experimental Therapeutics, vol. 242, no. 2, pp. 548-551, 1987.

[116] C. J. Vaughan, A. M. Aherne, E. Lane, O. Power, R. M. Carey, and D. P. O'Connell, "Identification and regional distribution of the dopamine $\mathrm{D}_{1 \mathrm{~A}}$ receptor in the gastrointestinal tract," American Journal of Physiology, vol. 279, no. 2, pp. R599R609, 2000.

[117] S. J. Qualman, H. M. Haupt, P. Yang, and S. R. Hamilton, "Esophageal Lewy bodies associated with ganglion cell loss in achalasia. Similarity to Parkinson's disease," Gastroenterology, vol. 87, no. 4, pp. 848-856, 1984.

[118] W. J. Kupsky, M. M. Grimes, J. Sweeting, R. Bertsch, and L. J. Cote, "Parkinson's disease and megacolon: concentric hyaline inclusions (Lewy bodies) in enteric ganglion cells," Neurology, vol. 37, no. 7, pp. 1253-1255, 1987.

[119] K. Wakabayashi, H. Takahachi, E. Ohama, and F. Ikuta, "Parkinson's disease: an immunohistochemical study of Lewy body-containing neurons in the enteric nervous system," Acta Neuropathologica, vol. 79, no. 6, pp. 581-583, 1990.

[120] S. Takeda, K. Yamazaki, T. Miyakawa, and H. Arai, "Parkinson's disease with involvement of the parasympathetic ganglia," Acta Neuropathologica, vol. 86, no. 4, pp. 397-398, 1993.

[121] C. Singaram, W. Ashraf, E. A. Gaumnitz et al., "Dopaminergic defect of enteric nervous system in Parkinson's disease patients with chronic constipation," The Lancet, vol. 346, no. 8979, pp. 861-864, 1995

[122] Y. Haskel and M. Hanani, "Inhibition of gastrointestinal motility by MPTP via adrenergic and dopaminergic mechanisms," Digestive Diseases and Sciences, vol. 39, no. 11, pp. 2364-2367, 1994.

[123] T. Banach, D. Zurowski, K. Gil, A. Krygowska-Wajs, A. Marszalek, and P. J. Thor, "Peripheral mechanisms of intestinal dysmotility in rats with salsolinol induced experimental Parkinson's disease," Journal of Physiology and Pharmacology, vol. 57, no. 2, pp. 291-300, 2006.

[124] R. E. Drolet, J. R. Cannon, L. Montero, and J. T. Greenamyre, "Chronic rotenone exposure reproduces Parkinson's disease gastrointestinal neuropathology," Neurobiology of Disease, vol. 36, no. 1, pp. 96-102, 2009.

[125] T. Tanaka, L. H. VanKlompenberg, and M. G. Sarr, "Selective role of vagal and nonvagal innervation in initiation and coordination of gastric and small bowel patterns of interdigestive and postprandial motility," Journal of Gastrointestinal Surgery, vol. 5, no. 4, pp. 418-433, 2001.

[126] R. O. Dantas and R. C. M. Mamede, "Motility of the transverse colon used for esophageal replacement," Journal of Clinical Gastroenterology, vol. 34, no. 3, pp. 225-228, 2002.

[127] M. S. El-Bahnasawy, Y. Osman, M. A. Gomha, and A. A. Shaaban, "Persistent and occasional nocturnal enuresis in orthotopic urinary diversion: is there a urodynamic difference?" BJU International, vol. 96, no. 9, pp. 1373-1377, 2005.

[128] K. Wakabayashi and H. Takahashi, "Neuropathology of autonomic nervous system in Parkinson's disease," European Neurology, vol. 38 supplement 2, pp. 2-7, 1997.

[129] P. W. Nathan and M. C. Smith, "Spinal pathways subserving defaecation and sensation from the lower bowel," Journal of Neurology, Neurosurgery and Psychiatry, vol. 16, no. 4, pp. 245-256, 1953.

[130] T. Kanesaka, R. Sakakibara, S. Ito et al., "Intestinal pseudoobstruction in acute myelitis," Internal Medicine, vol. 45, no. 1, pp. 35-36, 2006.
[131] A. C. Lynch and F. A. Frizelle, "Colorectal motility and defecation after spinal cord injury in humans," Progress in Brain Research, vol. 152, pp. 335-343, 2005.

[132] Y. W. Chia, K. P. Gill, J. S. Jameson et al., "Paradoxical puborectalis contraction is a feature of constipation in patients with multiple sclerosis," Journal of Neurology, Neurosurgery and Psychiatry, vol. 60, no. 1, pp. 31-35, 1996.

[133] K. Krogh, C. Mosdal, and S. Laurberg, "Gastrointestinal and segmental colonic transit times in patients with acute and chronic spinal cord lesions," Spinal Cord, vol. 38, no. 10, pp. 615-621, 2000.

[134] R. Sakakibara, T. Yamaguchi, T. Uchiyama et al., "Calcium polycarbophil improves constipation in non-traumatic spinal cord disorders," Clinical Autonomic Research, vol. 16, no. 4, pp. 289-292, 2006.

[135] J. M. Park, D. A. Bloom, and E. J. McGuire, "The guarding reflex revisited," British Journal of Urology, vol. 80, no. 6, pp. 940-945, 1997.

[136] Y. S. Nout, G. M. Leedy, M. S. Beattie, and J. C. Bresnahan, "Alterations in eliminative and sexual reflexes after spinal cord injury: defecatory function and development of spasticity in pelvic floor musculature," Progress in Brain Research, vol. 152, pp. 359-372, 2005.

[137] J. R. Wood, M. Camilleri, P. A. Low, and J. R. Malagelada, "Brainstem tumor presenting as an upper gut motility disorder," Gastroenterology, vol. 89, no. 6, pp. 1411-1414, 1985.

[138] T. Ito, R. Sakakibara, Y. Sakakibara, M. Mori, and T. Hattori, "Medulla and gut," Internal Medicine, vol. 43, no. 11, p. 1091, 2004.

[139] W. P. Gai, W. W. Blessing, and P. C. Blumbergs, "Ubiquitinpositive degenerating neurites in the brainstem in Parkinson's disease," Brain, vol. 118, no. 6, pp. 1447-1459, 1995.

[140] J. Weber, P. Denis, B. Mihout et al., "Effect of brain-stem lesion on colonic and anorectal motility: study of three patients," Digestive Diseases and Sciences, vol. 30, no. 5, pp. 419-425, 1985.

[141] R. J. Valentino, M. Kosboth, M. Colflesh, and R. R. Miselis, "Transneuronal labeling from the rat distal colon: anatomic evidence for regulation of distal colon function by a pontine corticotropin-releasing factor system," Journal of Comparative Neurology, vol. 417, no. 4, pp. 399-414, 2000.

[142] G. Gravante, M. Sabatino, F. Sorbera, G. Ferraro, and V. La Grutta, "Effects of substantia nigra stimulation on electrical and mechanical activities of the duodeno-jejunal loop, in the cat," Archives Internationales de Physiologie et de Biochimie, vol. 93, no. 2, pp. 93-100, 1985.

[143] H. Jing, K. W. Lin, and M. H. Mei, "Participation of dopamine on the muscarinergic inhibitory effect of substance $P$ on gastric myoelectric activity and motility," Sheng Li Xue Bao, vol. 47, no. 3, pp. 245-252, 1995.

[144] W. R. G. Gibb, A. J. Lees, P. Jenner, and C. D. Marsden, "The dopamine neurotoxin 1-methyl-4-phenyl-1,2,3,6tetrahydropyridine (MPTP) produces histological lesions in the hypothalamus of the common marmoset," Neuroscience Letters, vol. 65, no. 1, pp. 79-83, 1986.

[145] L. Bueno, M. Gue, C. Fabre, and J. L. Junien, "Involvement of central dopamine and D1 receptors in stress-induced colonic motor alterations in rats," Brain Research Bulletin, vol. 29, no. 2, pp. 135-140, 1992.

[146] V. Bagaev and V. Aleksandrov, "Visceral-related area in the rat insular cortex," Autonomic Neuroscience: Basic and Clinical, vol. 125, no. 1-2, pp. 16-21, 2006. 
[147] M. P. Jones, J. B. Dilley, D. Drossman, and M. D. Crowell, "Brain-gut connections in functional GI disorders: anatomic and physiologic relationships," Neurogastroenterology and Motility, vol. 18, no. 2, pp. 91-103, 2006.

[148] R. B. C. Kavia, R. Dasgupta, and C. J. Fowler, "Functional imaging and the central control of the bladder," Journal of Comparative Neurology, vol. 493, no. 1, pp. 27-32, 2005.

[149] L. L. Edwards, R. F. Pfeiffer, E. M. M. Quigley, R. Hofman, and M. Balluff, "Gastrointestinal symptoms in Parkinson's disease," Movement Disorders, vol. 6, no. 2, pp. 151-156, 1991.

[150] W. H. Jost, “Autonomic dysfunction in idiopathic Parkinson's disease," Journal of Neurology, vol. 250, supplement 1, pp. I28-I30, 2003.

[151] C. Magerkurth, R. Schnitzer, and S. Braune, "Symptoms of autonomic failure in Parkinson's disease: prevalence and impact on daily life," Clinical Autonomic Research, vol. 15, no. 2, pp. 76-82, 2005.

[152] A. K. Tuteja, N. J. Talley, S. K. Joos, J. V. Woehl, and D. H. Hickam, "Is constipation associated with decreased physical activity in normally active subjects?" American Journal of Gastroenterology, vol. 100, no. 1, pp. 124-129, 2005.

[153] J. W. Wiley, "Aging and neural control of the GI tract III: senescent enteric nervous system: lessons from extraintestinal sites and nonmammalian species," American Journal of Physiology, vol. 283, no. 5, pp. G1020-G1026, 2002.

[154] C. Singer, W. J. Weiner, and J. R. Sanchez-Ramos, "Autonomic dysfunction in men with Parkinson's disease," European Neurology, vol. 32, no. 3, pp. 134-140, 1992.

[155] M. F. Siddiqui, S. Rast, M. J. Lynn, A. P. Auchus, and R. F. Pfeiffer, "Autonomic dysfunction in Parkinson's disease: a comprehensive symptom survey," Parkinsonism and Related Disorders, vol. 8, no. 4, pp. 277-284, 2002.

[156] K. M. Robson, D. K. Kiely, and T. Lembo, "Development of constipation in nursing home residents," Diseases of the Colon and Rectum, vol. 43, no. 7, pp. 940-943, 2000.

[157] W. H. Jost and K. Schimrigk, "Constipation in Parkinson's disease," Klinische Wochenschrift, vol. 69, no. 20, pp. 906-909, 1991.

[158] S. J. Wang, J. L. Fuh, D. E. Shan et al., "Sympathetic skin response and R-R interval variation in Parkinson's disease," Movement Disorders, vol. 8, no. 2, pp. 151-157, 1993.

[159] R. D. Abbott, H. Petrovitch, L. R. White et al., "Frequency of bowel movements and the future risk of Parkinson's disease," Neurology, vol. 57, no. 3, pp. 456-462, 2001.

[160] R. Sakakibara, T. Odaka, T. Uchiyama et al., "Colonic transit time and rectoanal videomanometry in Parkinson's disease," Journal of Neurology, Neurosurgery and Psychiatry, vol. 74, no. 2, pp. 268-272, 2003.

[161] T. Yokoyama and I. Hasegawa, "Ileus in Parkinson's disease," Neurological Medicine, vol. 66, pp. 6-11, 2007.

[162] A. Lewitan, L. Nathanson, and W. R. Slade Jr., "Megacolon and dilatation of the small bowel in parkinsonism," Gastroenterology, vol. 17, no. 3, pp. 367-374, 1951.

[163] L. H. Caplan, H. G. Jacobson, B. M. Rubinstein, and M. Z. Rotman, "Megacolon and volvulus in Parkinson's disease," Radiology, vol. 85, pp. 73-79, 1965.

[164] M. J. Rosenthal and C. E. Marshall, "Sigmoid volvulus in association with parkinsonism: report of four cases," Journal of the American Geriatrics Society, vol. 35, no. 7, pp. 683-684, 1987.

[165] R. de Giorgio, S. Guerrini, G. Barbara, C. Cremon, V. Stanghellini, and R. Corinaldesi, "New insights into human enteric neuropathy," Neurogastroenterology and Motility, vol. 16, supplement 1, pp. 143-147, 2004.

[166] G. Bassotti and V. Villanacci, "Slow transit constipation: a functional disorder becomes an enteric neuropathy," World Journal of Gastroenterology, vol. 12, no. 29, pp. 4609-4613, 2006.

[167] W. H. Jost and B. Schrank, "Defecatory disorders in de novo Parkinsonians: colonic transit and electromyogram of the external anal sphincter," Wiener Klinische Wochenschrift, vol. 110, no. 15, pp. 535-537, 1998.

[168] L. L. Edwards, E. M. M. Quigley, R. K. Harned, R. Hofman, and R. F. Pfeiffer, "Characterisation of swallowing and defecation in Parkinson's disease," The American Journal of Gastroenterology, vol. 89, pp. 15-25, 1994.

[169] W. Ashraf, R. F. Pfeiffer, F. Park, J. Lof, and E. M. M. Quigley, "Constipation in Parkinson's disease: objective assessment and response to psyllium," Movement Disorders, vol. 12, no. 6, pp. 946-951, 1997.

[170] K. N. Davies, D. King, D. Billington, and J. A. Barrett, "Intestinal permeability and orocaecal transit time in elderly patients with Parkinson's disease," Postgraduate Medical Journal, vol. 72, no. 845, pp. 164-167, 1996.

[171] F. Stocchi, A. Carbone, M. Inghilleri et al., "Urodynamic and neurophysiological evaluation in Parkinson's disease and multiple system atrophy," Journal of Neurology, Neurosurgery and Psychiatry, vol. 62, no. 5, pp. 507-511, 1997.

[172] B. Frenckner and T. Ihre, "Influence of autonomic nerves on the internal anal sphincter in man," Gut, vol. 17, no. 4, pp. 306-312, 1976.

[173] L. L. Edwards, E. M. M. Quigley, R. K. Harned, R. Hofman, and R. F. Pfeiffer, "Defecatory function in Parkinson's disease: response to apomorphine," Annals of Neurology, vol. 33, no. 5, pp. 490-493, 1993.

[174] R. Sakakibara, T. Hattori, T. Uchiyama, and T. Yamanishi, "Videourodynamic and sphincter motor unit potential analyses in Parkinson's disease and multiple system atrophy," Journal of Neurology, Neurosurgery and Psychiatry, vol. 71, no. 5, pp. 600-606, 2001.

[175] D. C. Paviour, D. Williams, C. J. Fowler, N. P. Quinn, and A. J. Lees, "Is sphincter electromyography a helpful investigation in the diagnosis of multiple system atrophy? A retrospective study with pathological diagnosis," Movement Disorders, vol. 20, no. 11, pp. 1425-1430, 2005.

[176] M. A. Kamm, "Pelvic floor tests," in Constipation, M. A. Kamm and J. E. Lennard-Jones, Eds., chapter 17, pp. 145153, Wrightson Biomedical Publishing, Petersfield, UK, 1994.

[177] W. Ashraf, Z. K. Wszolek, R. F. Pfeiffer et al., "Anorectal function in fluctuating (on-off) Parkinson's disease: evaluation by combined anorectal manometry and electromyography," Movement Disorders, vol. 10, no. 5, pp. 650-657, 1995.

[178] F. de Lorijn, W. J. de Jonge, T. Wedel, J. M. Vanderwinden, M. A. Benninga, and G. E. Boeckxstaens, "Interstitial cells of Cajal are involved in the afferent limb of the rectoanal inhibitory reflex," Gut, vol. 54, no. 8, pp. 1107-1113, 2005.

[179] A. MacDonald, P. J. Paterson, J. N. Baxter, and I. G. Finlay, "Relationship between intra-abdominal and intrarectal pressure in the proctometrogram," British Journal of Surgery, vol. 80, no. 8, pp. 1070-1071, 1993.

[180] S. Iscoe, "Control of abdominal muscles," Progress in Neurobiology, vol. 56, no. 4, pp. 433-506, 1998.

[181] G. A. Fontana, T. Pantaleo, F. Lavorini, F. Benvenuti, and S. Gangemi, "Defective motor control of coughing in Parkinson's disease," American Journal of Respiratory and Critical Care Medicine, vol. 158, no. 2, pp. 458-464, 1998. 
[182] S. E. Mathers, P. A. Kempster, P. J. Law et al., "Anal sphincter dysfunction in Parkinson's disease," Archives of Neurology, vol. 46, no. 10, pp. 1061-1064, 1989.

[183] L. Edwards, E. M. M. Quigley, R. Hofman, and R. F. Pfeiffer, "Gastrointestinal symptoms in Parkinson disease: 18-month follow-up study," Movement Disorders, vol. 8, no. 1, pp. 8386, 1993.

[184] N. W. Read and J. M. Timms, "Defecation and the pathophysiology of constipation," Clinics in Gastroenterology, vol. 15, no. 4, pp. 937-965, 1986.

[185] G. Bassotti, D. Maggio, E. Battaglia et al., "Manometric investigation of anorectal function in early and late stage Parkinson's disease," Journal of Neurology, Neurosurgery and Psychiatry, vol. 68, no. 6, pp. 768-770, 2000.

[186] G. J. Oettle, "Effect of moderate exercise on bowel habit," Gut, vol. 32, no. 8, pp. 941-944, 1991.

[187] A. Ueki and M. Otsuka, "Life style risks of Parkinson's disease: association between decreased water intake and constipation," Journal of Neurology, vol. 251, supplement 7, pp. 18-23, 2004.

[188] W. Bosshard, R. Dreher, J. F. Schnegg, and C. J. Büla, "The treatment of chronic constipation in elderly people: an update," Drugs and Aging, vol. 21, no. 14, pp. 911-930, 2004.

[189] M. B. Roberfroid, "Health benefits of non-digestible oligosaccharides," Advances in Experimental Medicine and Biology, vol. 427, pp. 211-219, 1997.

[190] R. Astarloa, M. A. Mena, V. Sanchez, L. de la Vega, and J. G. de Yebenes, "Clinical and pharmacological effects of a diet rich in insoluble fiber on Parkinson's disease," Clinical Neuropharmacology, vol. 15, pp. 375-380, 1992.

[191] T. E. Eichhorn and W. H. Oertel, "Macrogol 3350/electrolyte improves constipation in Parkinson's disease and multiple system atrophy," Movement Disorders, vol. 16, no. 6, pp. 1176-1177, 2001.

[192] R. Sakakibara, T. Yamaguchi, T. Uchiyama et al., "Calcium polycarbophil improves constipation in primary autonomic failure and multiple system atrophy subjects," Movement Disorders, vol. 22, no. 11, pp. 1672-1673, 2007.

[193] K. Sadjadpour, "Pyridostigmine bromide and constipation in Parkinson's disease," Journal of the American Medical Association, vol. 249, no. 9, pp. 1148-1149, 1983.

[194] A. Dive, F. Foret, J. Jamart, P. Bulpa, and E. Installe, "Effect of dopamine on GI motility during criticall illness," Intensive Care Medicine, vol. 26, pp. 901-907, 2000.

[195] L. Marzio, M. Neri, O. Pieramico, M. Delle Donne, T. L. Peeters, and F. Cuccurullo, "Dopamine interrupts gastrointestinal fed motility pattern in humans: effect on motilin and somatostatin blood levels," Digestive Diseases and Sciences, vol. 35, no. 3, pp. 327-332, 1990.

[196] G. A. Lanfranchi, G. Bazzocchi, F. Fois, C. Brignola, M. Campieri, and B. Menni, "Effect of domperidone and dopamine on colonic motor activity in patients with the irritable bowel syndrome," European Journal of Clinical Pharmacology, vol. 29, no. 3, pp. 307-310, 1985.

[197] O. Hornykiewicz and S. J. Kish, "Biochemical pathophysiology of Parkinson's disease," Advances in Neurology, vol. 45, pp. 19-34, 1986.

[198] F. Bermejo Pareja, P. Martinez-Martin, V. Muradas, and J. G. de Yebenes, "Carbidopa dosage modifies L-dopa induced side effects and blood levels of L-dopa and other amino acids in advanced parkinsonism," Acta Neurologica Scandinavica, vol. 72 , no. 5, pp. 506-511, 1985.
[199] M. Tonini, "Recent advances in the pharmacology of gastrointestinal prokinetics," Pharmacological Research, vol. 33, no. 4-5, pp. 217-226, 1996.

[200] M. Soykan, I. Sarosiek, J. Shifflett, G. F. Wooten, and R. W. McCallum, "Effect of chronic oral domperidone therapy on gastrointestinal symptoms and gastric emptying in patients with Parkinson's disease," Movement Disorders, vol. 12, no. 6, pp. 952-957, 1997.

[201] S. S. Iyer, J. C. Morgan, and K. D. Sethi, "Absorption of orally disintegrating carbidopalevodopa requires intact small bowel function," Neurology, vol. 65, no. 9, p. 1507, 2005.

[202] J. S. Shindler, G. T. Finnerty, K. Towlson, A. L. Dolan, C. L. Davies, and J. D. Parkes, "Domperidone and levodopa in Parkinson's disease," British Journal of Clinical Pharmacology, vol. 18, no. 6, pp. 959-962, 1984.

[203] W. D. Neira, V. Sanchez, M. A. Mena, and J. G. de Yebenes, "The effects of Cisapride on plasma L-dopa levels and clinical response in Parkinson's disease," Movement Disorders, vol. 10, no. 1, pp. 66-70, 1995.

[204] N. Langdon, P. N. Malcolm, and J. D. Parkes, "Comparison of levodopa with carbidopa, and levodopa with domperidone in Parkinson's disease," Clinical Neuropharmacology, vol. 9, no. 5, pp. 440-447, 1986.

[205] R. Djaldetti, M. Koren, I. Ziv, A. Achiron, and E. Melamed, "Effect of Cisapride on response fluctuations in Parkinson's disease," Movement Disorders, vol. 10, no. 1, pp. 81-84, 1995.

[206] W. H. Jost and K. Schimrigk, "Long-term results with cisapride in Parkinson's disease," Movement Disorders, vol. 12, no. 3, pp. 423-425, 1997.

[207] A. P. Sempere, J. Duarte, C. Cabezas, L. E. Claveria, and F. Coria, "Aggravation of parkinsonian tremor by cisapride," Clinical Neuropharmacology, vol. 18, no. 1, pp. 76-78, 1995.

[208] A. Inui, T. Yoshikawa, R. Nagai, N. Yoshida, and T. Ito, "Effects of mosapride citrate, a 5-HT4 receptor agonist, on colonic motility in conscious guinea pigs," Japanese Journal of Pharmacology, vol. 90, no. 4, pp. 313-320, 2002.

[209] H. Asai, F. Udaka, M. Hirano et al., "Increased gastric motility during 5-HT4 agonist therapy reduces response fluctuations in Parkinson's disease," Parkinsonism and Related Disorders, vol. 11, no. 8, pp. 499-502, 2005.

[210] Z. Liu, R. Sakakibara, T. Odaka et al., "Mosapride citrate, a novel 5-HT4 agonist and partial 5-HT3 antagonist, amerliorates constipation in parkinsonian patients," Movement Disorders, vol. 20, no. 6, pp. 680-686, 2005.

[211] H. Iida, H. Inada, H. Tanaka, T. Nagasaka, K. Shindo, and Z. Shiozawa, "Effects of antiemetic drugs in combination with a dopamine receptor agonist, pergolide, on Parkinson's disease: a comparison between domperidone and mosapride," Neurological Therapeutics, vol. 19, no. 1, pp. 57-62, 2002.

[212] K. L. Sullivan, J. F. Staffetti, R. A. Hauser, P. B. Dunne, and T. A. Zesiewicz, "Tegaserod (Zelnorm) for the treatment of constipation in Parkinson's disease," Movement Disorders, vol. 21, no. 1, pp. 115-116, 2006.

[213] K. Maganti, K. Onyemere, and M. P. Jones, "Oral erythromycin and symptomatic relief of gastroparesis: a systematic review," American Journal of Gastroenterology, vol. 98, no. 2, pp. 259-263, 2003.

[214] R. F. Pfeiffer, K. Markopoulou, E. M. M. Quigley, N. Stambler, and J. M. Cedarbaum, "Effect of NT-3 on bowel function in Parkinson's disease," Movement Disorders, vol. 17, pp. 223-224, 2002.

[215] R. Sandyk and M. A. Gillman, "Colchicine ameliorates constipation in Parkinson's disease," Journal of the Royal Society of Medicine, vol. 77, no. 12, p. 1066, 1984. 
[216] A. Albanese, G. Maria, A. Bentivoglio, G. Brisinda, E. Cassetta, and P. Tonali, "Severe constipation in Parkinson's disease relieved by botulinum toxin," Movement Disorders, vol. 12, no. 5, pp. 764-766, 1997.

[217] F. Cadeddu, A. R. Bentivoglio, F. Brandara, G. Marniga, G. Brisinda, and G. Maria, "Outlet type constipation in Parkinson's disease: results of botulinum toxin treatment," Alimentary Pharmacology and Therapeutics, vol. 22, no. 10, pp. 997-1003, 2005.

[218] G. Chiarioni, S. Heymen, and W. E. Whitehead, "Biofeedback therapy for dyssynergic defecation," World Journal of Gastroenterology, vol. 12, no. 44, pp. 7069-7074, 2006.

[219] A. G. Papatsoris, C. Deliveliotis, C. Singer, and S. Papapetropoulos, "Erectile dysfunction in Parkinson's disease," Urology, vol. 67, no. 3, pp. 447-451, 2006.

[220] E. Brown, G. M. Brown, O. Kofman, and B. Quarrington, "Sexual function and affect in parkinsonian men treated with L-dopa," American Journal of Psychiatry, vol. 135, no. 12, pp. 1552-1555, 1978.

[221] R. G. Brown, M. Jahanshahi, N. Quinn, and C. D. Marsden, "Sexual function in patients with Parkinson's disease and their partners," Journal of Neurology, Neurosurgery and Psychiatry, vol. 53, no. 6, pp. 480-486, 1990.

[222] H. Lipe, W. T. Longstreth, T. D. Bird, and M. Linde, "Sexual function in married men with Parkinson's disease compared to married men with arthritis," Neurology, vol. 40, no. 9, pp. 1347-1349, 1990.

[223] M. Welsh, L. Hung, and C. H. Waters, "Sexuality in women with Parkinson's disease," Movement Disorders, vol. 12, no. 6, pp. 923-927, 1997.

[224] A. Argiolas and M. R. Melis, "Central control of penile erection: role of the paraventricular nucleus of the hypothalamus," Progress in Neurobiology, vol. 76, no. 1, pp. 1-21, 2005.

[225] C. Singer, W. J. Weiner, J. R. Sanchez-Ramos, and M. Ackerman, "Sexual dysfunction in men with Parkinson's disease," Journal of Neurologic Rehabilitation, vol. 3, pp. 199204, 1989.

[226] W. R. van Furth, G. Wolterink, and J. M. van Ree, "Regulation of masculine sexual behavior: involvement of brain opioids and dopamine," Brain Research Reviews, vol. 21, no. 2, pp. 162-184, 1995.

[227] J. M. Dominguez and E. M. Hull, "Dopamine, the medial preoptic area, and male sexual behavior," Physiology and Behavior, vol. 86, no. 3, pp. 356-368, 2005.

[228] A. Tsujimura, Y. Miyagawa, K. Fujita et al., "Brain processing of audiovisual sexual stimuli inducing penile erection: a positron emission tomography study," Journal of Urology, vol. 176, no. 2, pp. 679-683, 2006.

[229] C. Fisher, J. Gorss, and J. Zuch, "Cycle of penile erection synchronous with dreaming (REM) sleep," Archives of General Psychiatry, vol. 12, pp. 29-45, 1965.

[230] M. Hirshkowitz and M. H. Schmidt, "Sleep-related erections: clinical perspectives and neural mechanisms," Sleep Medicine Reviews, vol. 9, no. 4, pp. 311-329, 2005.

[231] J. W. Langston and L. S. Forno, "The hypothalamus in Parkinson disease," Annals of Neurology, vol. 3, no. 2, pp. 129$133,1978$.

[232] I. Z. Ben Zion, R. Tessler, L. Cohen et al., "Polymorphisms in the dopamine $\mathrm{D} 4$ receptor gene $(D R D 4)$ contribute to individual differences in human sexual behavior: desire, arousal and sexual function," Molecular Psychiatry, vol. 11, pp. 782-786, 2006.

[233] G. Bellomo, L. Santambrogio, M. Fiacconi, A. M. Scarponi, and G. Ciuffetti, "Plasma profiles of adrenocorticotropic hormine, cortisol, growth hormone and prolactin in patients with untreated Parkinson's disease," Journal of Neurology, vol. 238, pp. 19-22, 1991.

[234] N. Martin-Alguacil, J. Schober, L. M. Kow, and D. Pfaff, "Arousing properties of the vulvar epithelium," Journal of Urology, vol. 176, no. 2, pp. 456-462, 2006.

[235] N. Martin-Alguacil, J. M. Schober, D. R. Sengelaub, D. W. Pfaff, and D. N. Shelley, "Clitoral sexual arousal: neuronal tracing study from the clitoris through the spinal tracts," Journal of Urology, vol. 180, no. 4, pp. 1241-1248, 2008.

[236] R. Munarriz, S. W. Kim, N. N. Kim et al., "A review of the physiology and pharmacology of peripheral (vaginal and clitoral) female genital arousal in the animal model," Journal of Urology, vol. 170, no. 2, part 2, pp. S40-S45, 2003.

[237] D. Pfaff, J. Frohlich, and M. Morgan, "Hormonal and genetic influences on arousal-sexual and otherwise," Trends in Neurosciences, vol. 25, no. 1, pp. 45-50, 2002.

[238] H. Gelez, S. Poirier, P. Facchinetti et al., "Neuroanatomical evidence for a role of central melanocortin-4 receptors and oxytocin in the efferent control of the rodent clitoris and vagina," Journal of Sexual Medicine, vol. 7, no. 6, pp. 20562067, 2010.

[239] B. R. Komisaruk and B. Whipple, "Functional MRI of the brain during orgasm in women," Annual Review of Sex Research, vol. 16, pp. 62-86, 2005.

[240] C. A. Pedersen and M. L. Boccia, "Oxytocin maintains as well as initiates female sexual behavior: effects of a highly selective oxytocin antagonist," Hormones and Behavior, vol. 41, no. 2, pp. 170-177, 2002.

[241] T. A. Baskerville and A. J. Douglas, "Dopamine and oxytocin interactions underlying behaviors: potential contributions to behavioral disorders," CNS Neuroscience and Therapeutics, vol. 16, no. 3, pp. e92-e123, 2010.

[242] M. D. Graham and J. G. Pfaus, "Differential regulation of female sexual behaviour by dopamine agonists in the medial preoptic area," Pharmacology Biochemistry and Behavior, vol. 97, no. 2, pp. 284-292, 2010.

[243] C. A. Frye and A. A. Walf, "Infusions of anti-sense oligonucleotides for DARPP-32 to the ventral tegmental area reduce effects of progesterone- and a dopamine type 1-like receptor agonist to facilitate lordosis," Behavioural Brain Research, vol. 206, no. 2, pp. 286-292, 2010.

[244] H. Jacobs, A. Vieregge, and P. Vieregge, "Sexuality in young patients with Parkinson's disease: a population based comparison with healthy controls," Journal of Neurology, Neurosurgery and Psychiatry, vol. 69, no. 4, pp. 550-552, 2000.

[245] G. Bronner, V. Royter, A. D. Korczyn, and N. Giladi, "Sexual dysfunction in Parkinson's disease," Journal of Sex and Marital Therapy, vol. 30, no. 2, pp. 95-105, 2004.

[246] M. Welsh, L. Hung, and C. H. Waters, "Sexuality in women with Parkinson's disease," Movement Disorders, vol. 12, no. 6, pp. 923-927, 1997.

[247] L. Wermuth and E. Stenager, "Sexual problems in young patients with Parkinson's disease," Acta Neurologica Scandinavica, vol. 91, no. 6, pp. 453-455, 1995.

[248] K. M. MacLennan, A. Boshier, L. V. Wilton, and S. A. W. Shakir, "Examination of the safety and use of apomorphine prescribed in general practice in England as a treatment for erectile dysfunction," BJU International, vol. 98, no. 1, pp. 125-131, 2006.

[249] J. D. O'Sullivan, "Apomorphine as an alternative to sildenafil in Parkinson's disease," Journal of Neurology, Neurosurgery and Psychiatry, vol. 72, no. 5, p. 681, 2002. 
[250] D. Deleu, Y. Hanssens, and M. G. Northway, "Subcutaneous apomorphine: an evidence-based review of its use in Parkinson's disease," Drugs and Aging, vol. 21, no. 11, pp. 687-709, 2004.

[251] M. R. Safarinejad, "Salvage of sildenafil failures with cabergoline: a randomized, double-blind, placebo-controlled study," International Journal of Impotence Research, vol. 18, no. 6, pp. 550-558, 2006.

[252] M. Pohankaa, P. Kanovsky, M. Bares, J. Pulkrabekb, and I. Rektorb, "The long-lasting improvement of sexual dysfunction in patients with advanced, fluctuating Parkinson's disease induced by pergolide: evidence from the results of an open, prospective, one-year trial," Parkinsonism and Related Disorders, vol. 11, no. 8, pp. 509-512, 2005.

[253] K. J. Klos, J. H. Bower, K. A. Josephs, J. Y. Matsumoto, and J. E. Ahlskog, "Pathological hypersexuality predominantly linked to adjuvant dopamine agonist therapy in Parkinson's disease and multiple system atrophy," Parkinsonism and Related Disorders, vol. 11, no. 6, pp. 381-386, 2005.

[254] B. L. Kessel, "A case of hedonistic homeostatic dysregulation," Age and Ageing, vol. 35, no. 5, pp. 540-541, 2006.

[255] L. Castelli, P. Perozzo, M. L. Genesia et al., "Sexual well being in parkinsonian patients after deep brain stimulation of the subthalamic nucleus," Journal of Neurology, Neurosurgery and Psychiatry, vol. 75, no. 9, pp. 1260-1264, 2004.

[256] L. M. Romito, M. Raja, A. Daniele et al., "Transient mania with hypersexuality after surgery for high-frequency stimulation of the subthalamic nucleus in Parkinson's disease," Movement Disorders, vol. 17, no. 6, pp. 1371-1374, 2002.

[257] I. F. Hussain, C. M. Brady, M. J. Swinn, C. J. Mathias, and C. J. Fowler, "Treatment of erectile dysfunction with sildenafil citrate (Viagra) in parkinsonism due to Parkinson's disease or multiple system atrophy with observations on orthostatic hypotension," Journal of Neurology, Neurosurgery \& Psychiatry, vol. 71, no. 3, pp. 371-374, 2001.

[258] R. Raffaele, I. Vecchio, B. Giammusso, G. Morgia, M. B. Brunetto, and L. Rampello, "Efficacy and safety of fixeddose oral sildenafil in the treatment of sexual dysfunction in depressed patients with idiopathic Parkinson's disease," European Urology, vol. 41, no. 4, pp. 382-386, 2002.

[259] M. R. Safarinejad and S. Y. Hosseini, "Salvage of sildenafil failures with bremelanotide: a randomized, double-blind, placebo controlled study," Journal of Urology, vol. 179, no. 3, pp. 1066-1071, 2008.

[260] C. C. Yang, Y. Y. Cao, Q. Y. Guan et al., "Influence of PDE5 inhibitor on MRI measurement of clitoral volume response in women with FSAD: a feasibility study of a potential technique for evaluating drug response," International Journal of Impotence Research, vol. 20, no. 1, pp. 105-110, 2008.

[261] M. L. Chivers and R. C. Rosen, "Phosphodiesterase type 5 inhibitors and female sexual response: faulty protocols or paradigms?" Journal of Sexual Medicine, vol. 7, no. 2, part 2, pp. 858-872, 2010.

[262] A. M. Shadiack, S. D. Sharma, D. C. Earle, C. Spana, and T. J. Hallam, "Melanocortins in the treatment of male and female sexual dysfunction," Current Topics in Medicinal Chemistry, vol. 7, no. 11, pp. 1137-1144, 2007. 


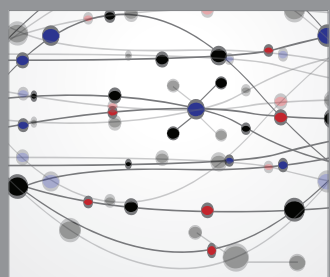

The Scientific World Journal
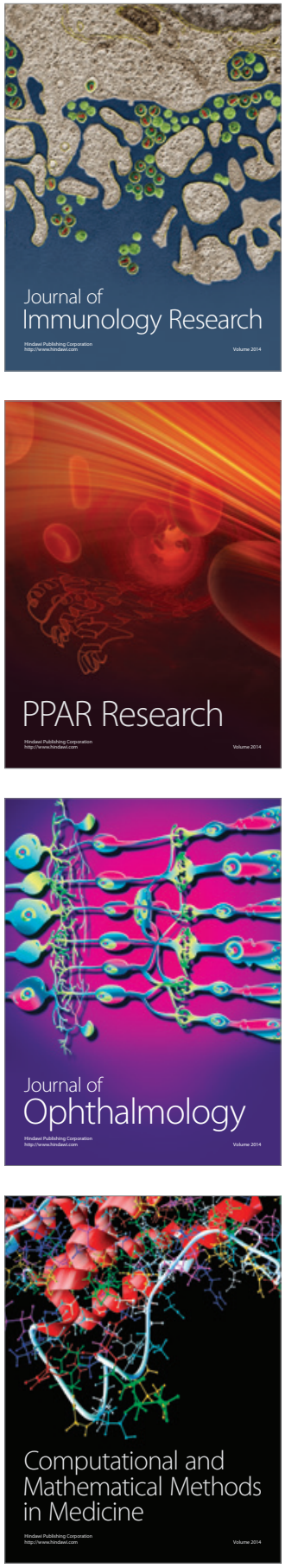

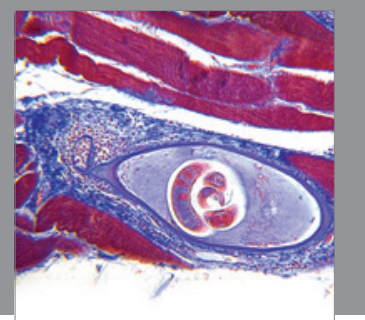

Gastroenterology

Research and Practice
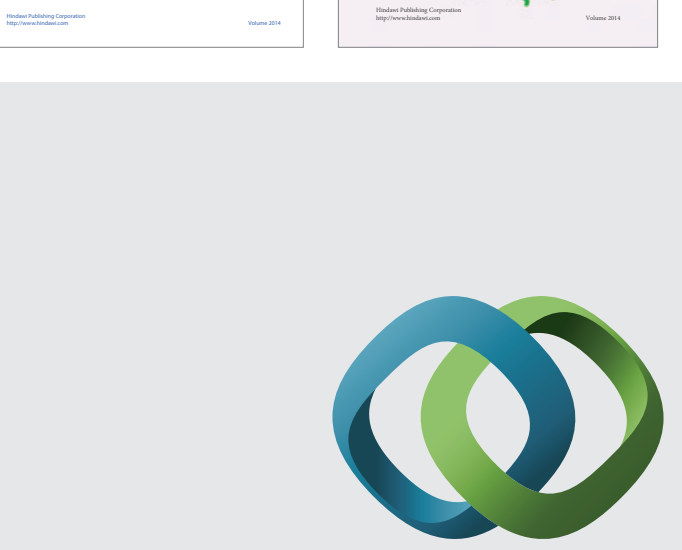

\section{Hindawi}

Submit your manuscripts at

http://www.hindawi.com
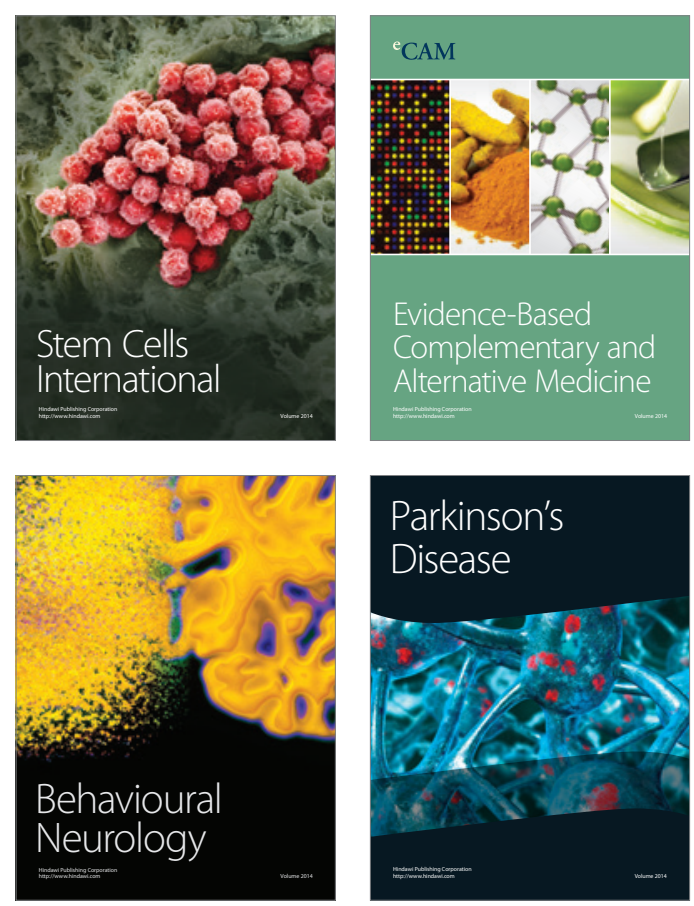

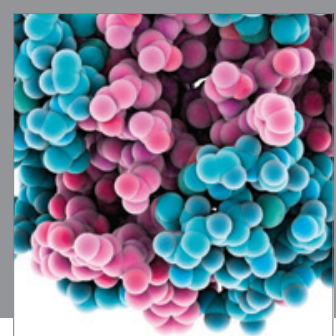

Journal of
Diabetes Research

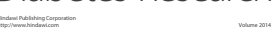

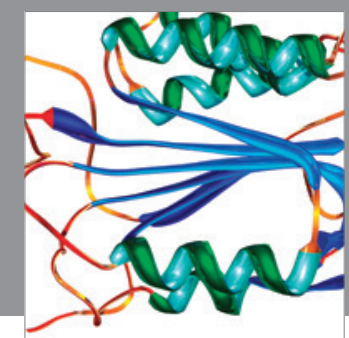

Disease Markers
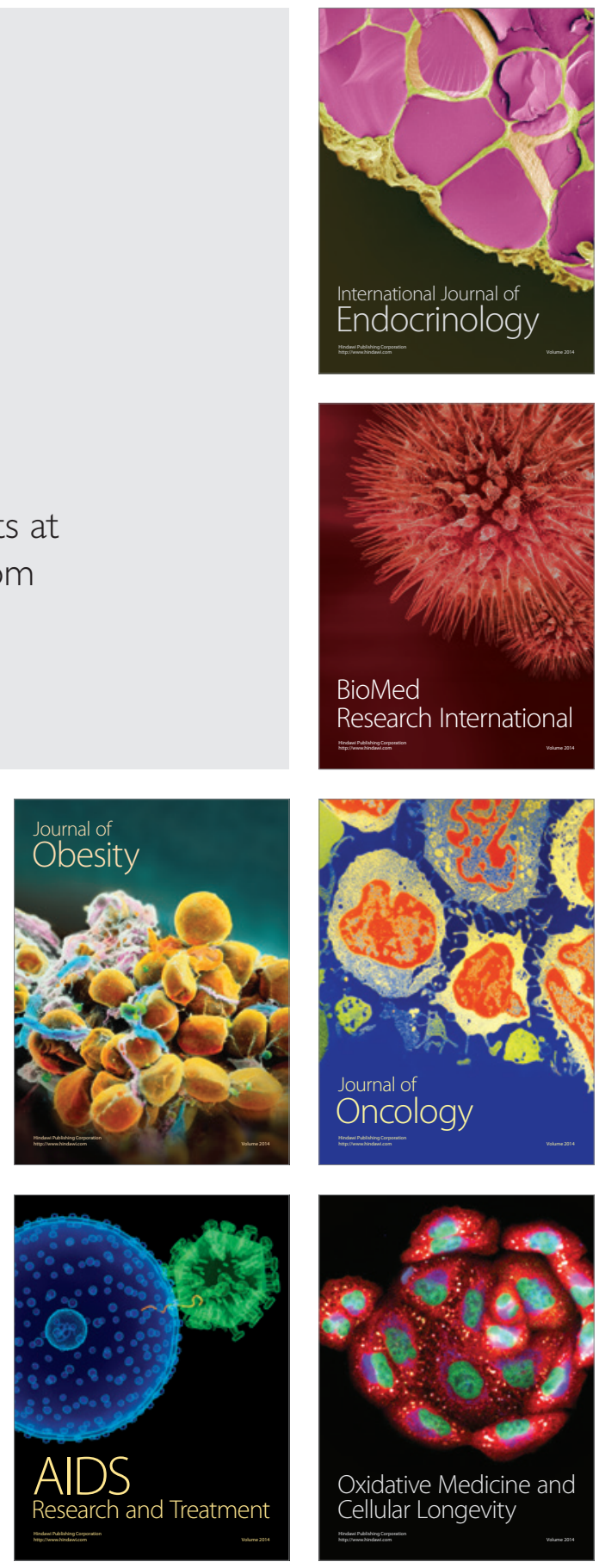